\title{
Climate Risk and Early Warning Systems: Adaptation Strategies for the Most Vulnerable Communities
}

\section{Jessica Bhardwaj ${ }^{1,2,3}, \underline{\text { Atifa Asghari }}^{1,2}$, Isabella Aitkenhead $^{1,2,3}$, Madeleine Jackson ${ }^{3,4}$, Yuriy Kuleshov $^{2,3,5}$}

${ }^{1}$ Monash University, Clayton, Victoria, Australia

${ }^{2}$ Bureau of Meteorology, Docklands, Victoria, Australia

3Royal Melbourne Institute of Technology (RMIT) University, Melbourne, Victoria, Australia

4The University of Liverpool, Liverpool, United Kingdom

${ }^{5}$ The University of Melbourne, Parkville, Victoria, Australia

https://doi.org/10.38126/ISPG180201

Corresponding author: yuriy.kuleshov@bom.gov.au

Keywords: climate risk; climate adaptation; Post Disaster Reviews; risk assessment; user-centered integrated early warning system; drought; floods; tropical cyclones

Executive Summary: Climate risk and resultant natural disasters have significant impacts on human and natural environments. It is common for disaster responses to be reactive rather than proactive due to inadequate policy and planning mechanisms-such reactive management responses exacerbate human and economic losses in times of disaster. Proactive disaster responses maximize disaster resilience and preparation efforts in non-disaster periods. This report focuses on proactive, localized, and inclusive adaptation strategies for addressing impacts of three natural hazards: drought, floods, and tropical cyclones. Four key synergistic climate adaptation strategies are discussed-Post Disaster Reviews, Risk Assessments, Early Warning Systems and Forecast-based Financing. These strategies are further supported with a number of case studies and recommendations that will be of assistance for policymakers in developing evidence-based adaptation strategies that support the most vulnerable communities in the transition towards regarding disaster as a risk as opposed to a crisis.

\section{Introduction}

Natural hazards caused by meteorological, climatological, and hydrological phenomena are the result of complex seasonal, yearly, and decadal climate variabilities as well as anthropogenic climate change. Natural hazards frequently progress into disasters and cause significant damage to vulnerable and exposed communities across the world. The impacts of natural hazards are already dire with an estimated 2.9 billion people affected by natural disasters and a projected 1.7 trillion USD worth of economic damage caused between 2000 and 2012 (Banholzer, Kossin, and Donner 2014). Under anthropogenic climate change, there is an expected increase in the frequency, severity and duration of meteorological, climatological and hydrological natural hazards (Intergovernmental Panel on Climate Change 2014). This means that vulnerable communities will face increased risk of death, injury and disrupted livelihood from events like tropical cyclones, floods, drought, etc.

The populations of Least Developed Countries (LDCs) and Small Island Developing States (SIDS) are particularly vulnerable to heightened disaster risk. Despite being referred to under the broad term of LDCs and SIDS, these countries have immensely diverse physical, historical and climatological characteristics (Hennessy, Power, and Cambers 2011). They do, however, share similar 
vulnerabilities, including low capacity to monitor and predict disasters and fragile economic and political environments, making them increasingly sensitive to the impacts of natural disasters. As a result, the 2020 World Risk Report found Pacific Island Country (PIC) Vanuatu to be exposed to the highest level of disaster risk in the world. The report also identified other PICs such as Tonga, Solomon Islands, and Papua New Guinea to be in the top 15 most-at-risk countries in the world (Behlert et al. 2020). Since the majority of this region is inherently dependent on the natural environment for food, water, and income, the implementation of appropriate adaptation strategies and early warning mechanisms are imperative (United Nations Office for Disaster Risk Reduction (UNDRR) and United Nations Development Programme (UNDP) 2012).

Results presented in this report contribute to implementing the Climate Risk and Early Warning Systems (CREWS) initiative (https://www.crewsinitiative.org/), the goal of which is to support LDC and SIDS in strengthening risk-informed early warning services for vulnerable communities.

Disaster Risk Reduction (DRR) is defined as "the systematic development and application of policies, strategies and practices to minimize vulnerabilities, hazards and the unfolding of disaster impacts throughout a society, in the broad context of sustainable development" (United Nations Office for Disaster Risk Reduction 2004). This increased focus on disaster preparation can lessen the severity of disaster response (see Figure 1 adapted from Wilhite, Sivakumar, and Pulwarthy 2014).

Our report examines DRR using four key synergistic climate adaptation strategies: Post Disaster Reviews, Risk Assessments, user-centered Integrated Early Warning Systems and Forecast-based Financing. We examine these strategies by combining literature review with specialized case studies conducted in our teams' project work.

These strategies are widely acknowledged to be DRR strategies themselves but in the context of our work, we emphasize that their implementation should complement other pre-existing DRR strategies at the national and sub-national scale to ensure that they align with the broader Disaster Risk Management policies, laws and plans in the region (Twigg 2015).
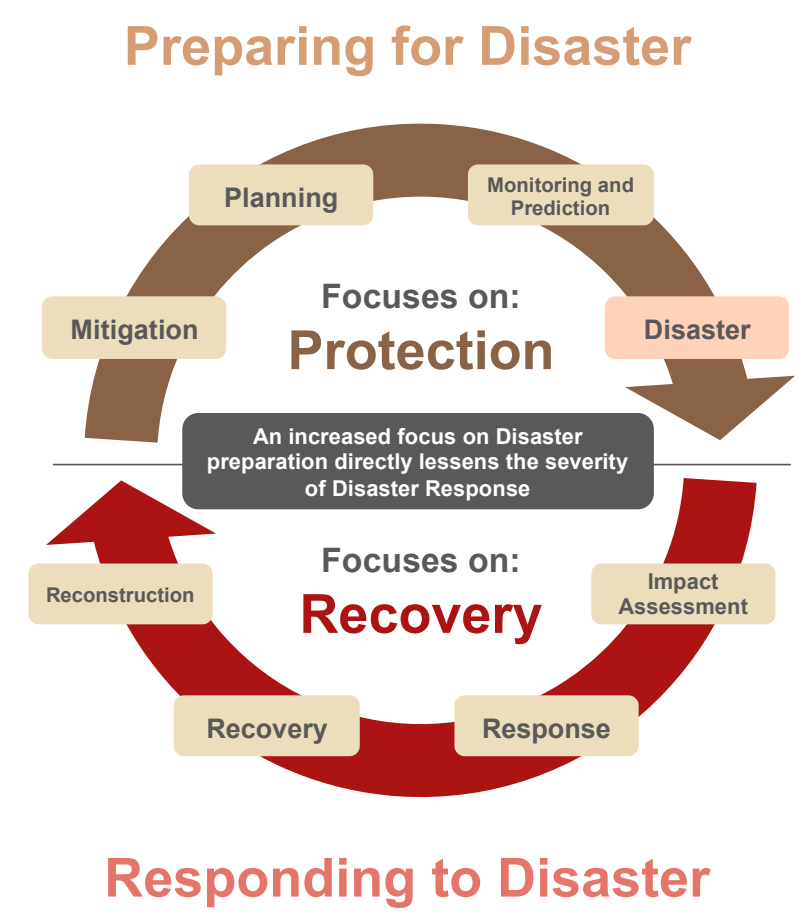

Figure 1: The Disaster Management cycle-preparing for disaster lessens the severity of responding to disaster.

We chose these strategies due to our extensive experience in analyzing and implementing them and their efficacy in reducing disaster risk for vulnerable communities (Twigg 2015). These strategies have several key interconnections and flows between them:

- Post Disaster Reviews (PDRs) inform the delivery of risk assessments and are also used to iterate and improve Early Warning System (EWS) design.

- Risk Assessments allow for a more informed and prioritized delivery of EWSs in the regions that are most at risk and results can also be used to prioritize funding allocations.

- EWSs can be used to trigger appropriate early action financing mechanisms that preallocate disaster response funds.

- Then the efficacy of all these strategies can be re-evaluated and iterated in the next PDR.

A schematic illustrating these flow and interconnections is provided in Figure 2. 


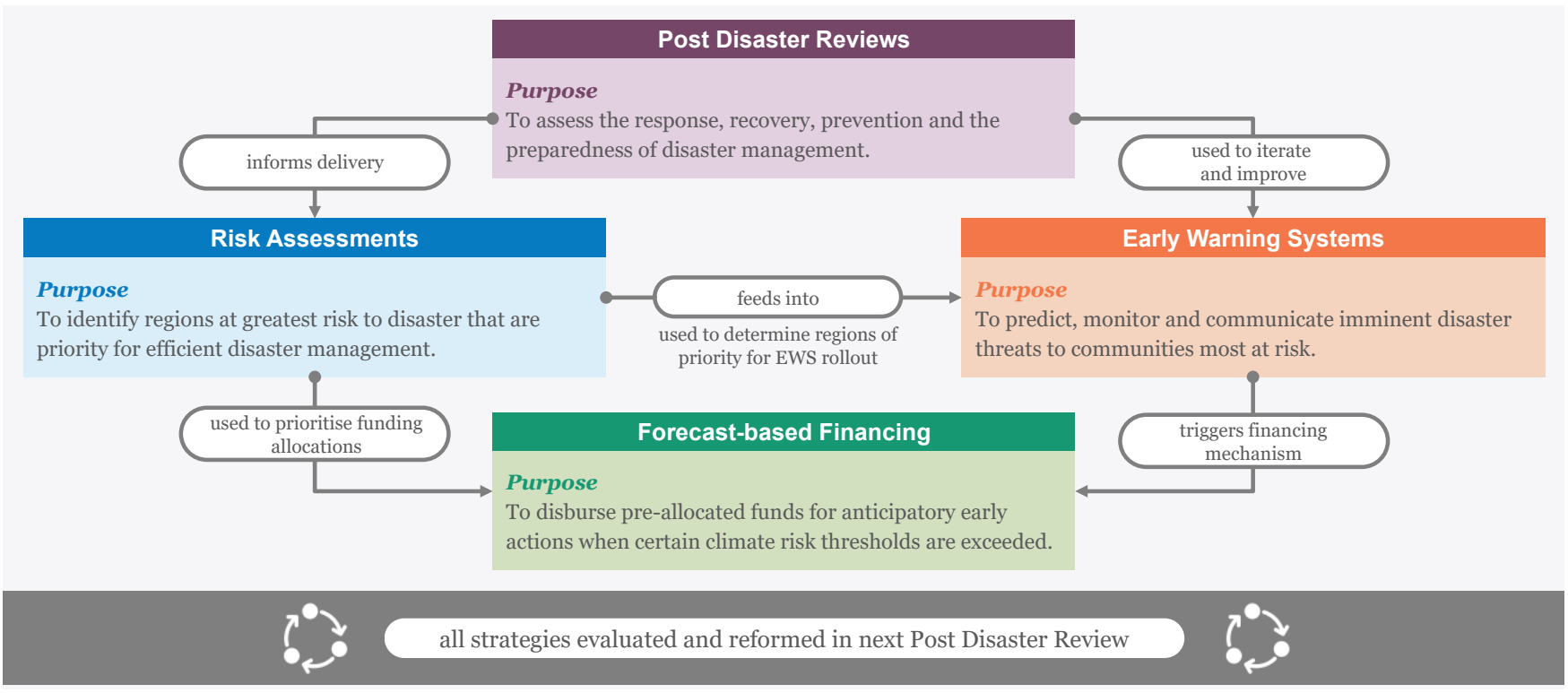

Figure 2: Interconnections between the four climate adaptation strategies presented in this report.

\section{Post Disaster Reviews}

Post Disaster Reviews (PDRs) are a key component of proactive disaster management that inform a more efficient EWS operation. PDRs are conducted in response to natural disasters. They produce data about the impact of disasters and analyses of losses, damages, and priority recovery actions. This helps to provide insight into key areas of improvement for the future management of disasters. PDRs help drive recovery beyond just physical reconstruction but towards comprehensive and resilient development strategies.

\section{i. Multi-hazards associated with tropical cyclones}

Tropical cyclones (TCs) are one of the most destructive natural hazards which affect vulnerable coastal communities in the tropics. TCs are multihazardous events, with destructive winds, torrential rain often leading to floods and landslides, and storm surges. In the warming climate, it is likely that fewer TCs will form but a higher proportion of those that do will be intense, more damaging cyclones (Knutson et al. 2010).

PDRs are essential for strengthening EWSs and improving preparedness for impacts of TCs. We know from past experiences that often forecasts of TCs were accurate; however, the potential impacts were not properly considered or were underestimated, and the response was inadequate.
For example, in 2013 TC Haiyan (Yolanda) devastated the Philippines; more than 6,000 people were reported dead and the estimated damage to infrastructure and agriculture was more than USD 827 million (National Disaster Risk Reduction and Management Council 2014). A PDR revealed that many of the deaths were caused by the storm surge; it is likely that many lives could be saved with better knowledge of the specific TC impacts related to storm surges (World Meteorological Organization (WMO) 2014). Accurate warnings were issued for winds and heavy rain in time, and the government deployed planes and helicopters to the regions most likely to be affected. However, had there been better knowledge of the risks, particularly of the storm surge, it is likely that more extensive evacuations from exposed areas could have taken place sooner (World Meteorological Organization (WMO) 2015).

As TCs are multi-hazardous events, all factors which could present risks to local communities should be considered through PDRs. Lessons will be learnt, and issues addressed to improve user-centered integrated EWSs (I-EWSs) for TCs which in turn will improve preparedness of vulnerable communities. In the following case study, we present a PDR which assessed TC Winston's impacts on (a) population, (b) infrastructure, and (c) natural environment (Jackson 2020). 


\section{Case Study-Tropical Cyclone Winston, Fiji}

In 2016, Fiji experienced the South Pacific's strongest landfalling TC on record-severe TC Winston which was a category 5 storm with lifetime minimum central pressure $884 \mathrm{hPa}$ and $280 \mathrm{~km} / \mathrm{h}$ winds (Diamond 2020). The impacts of Winston in Fiji were disastrous, resulting in USD 1.4 billion of economic damage and 44 fatalities (Government of Fiji 2016; Terry and Lau 2018).

Fiji is a country made up of 333 islands and is classed as a SIDS, a name used to describe countries which are particularly exposed to natural disasters, that may have fragile environments and lack opportunity for economic development, due to their size or accessibility (Feeny 2010; Méheux 2007). Low-lying coral islands in Fiji are a vulnerable natural environment. Coral reefs are delicate and prone to damage by storm surges and cyclone-driven waves. They provide habitats for an abundance of marine species, which are essential for seafood consumed by indigenous Fijian communities.

\section{a) Impact on population}

The impact of TC Winston on Fiji's population was analyzed by quantifying the total population estimated to be within the TC path zone. The estimated population within the most destructive 50 $\mathrm{km}$ path zone was 347,969 (around $40 \%$ of the total population of Fiji; Figure 3). The area within $50 \mathrm{~km}$ of the TC path zone states that residents are 'extremely' to 'seriously' affected (Ministry of Health, 2016). The total population estimated within $100 \mathrm{~km}$ from the TC's path was 816,683 , which represents approximately $95 \%$ of the country's population. The actual extent of loss and damage to individuals by the event is unknown, however these results demonstrate that the impact of TC Winston was felt by almost the entire nation.

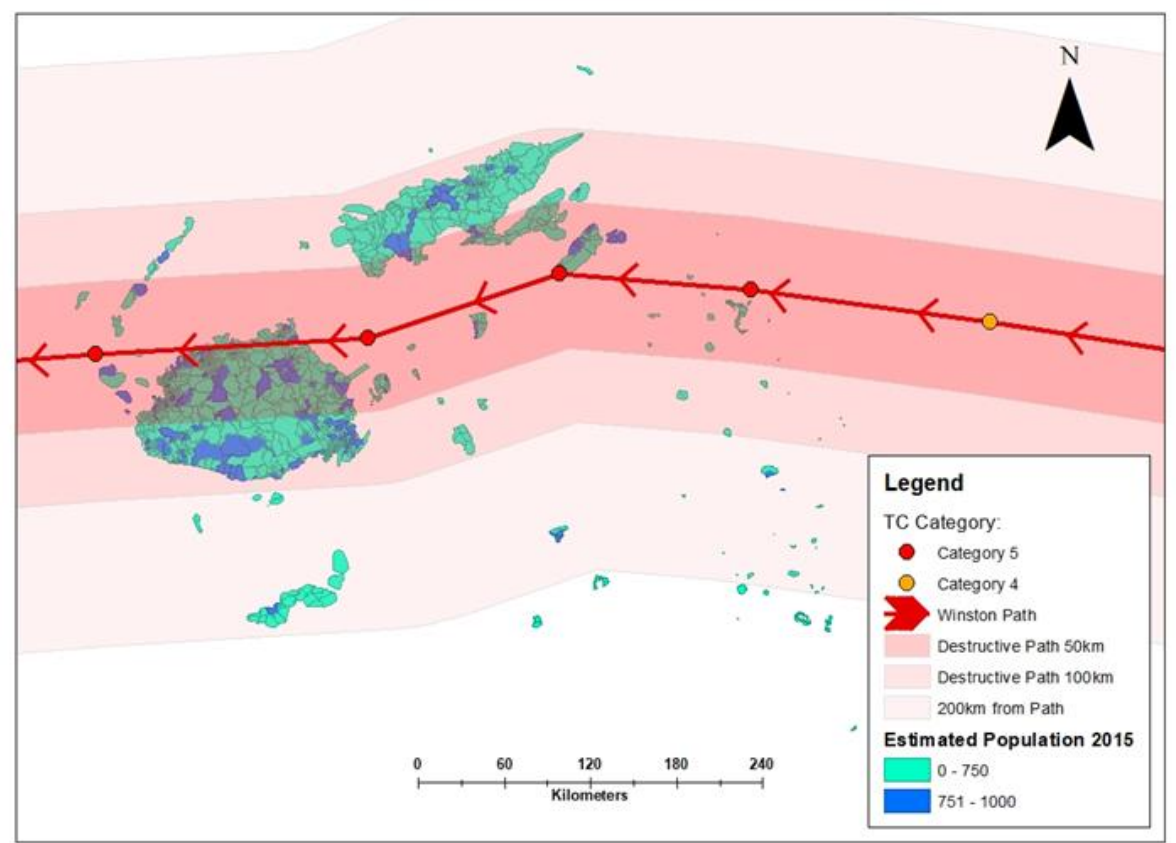

Figure 3: TC Winston path and Fiji population in 2015.

Data sources include: Spatial data for TC path provided by the Australian Bureau of Meteorology. Fiji boundary downloaded from Fiji Administrative Boundaries HDX (2019) (HDX 2019a) and population data acquired from PopGIS Statistics for Development Division (2019) (Statistics for Development Division 2019). 


\section{b) Impact on infrastructure}

Storm surges pose great risk to infrastructure built close to the coastline (Government of Fiji, 2016). Storm surge observation data around Fiji was mapped to assess the destructive impacts of TC Winston on infrastructure. Around $30 \%$ of the hospitals in Fiji as well as $73 \mathrm{~km}$ of roads were within $0.2 \mathrm{~km}$ of the observed storm surges (Figure 4). In addition, 1 of the 3 communication towers were within $0.2 \mathrm{~km}$ of the observed storm surge locations.

The storm surge presented by TC Winston was one of the most significant causes of destruction, leading to the national communication systems going down and $80 \%$ of the country losing power (Government of Fiji 2016).

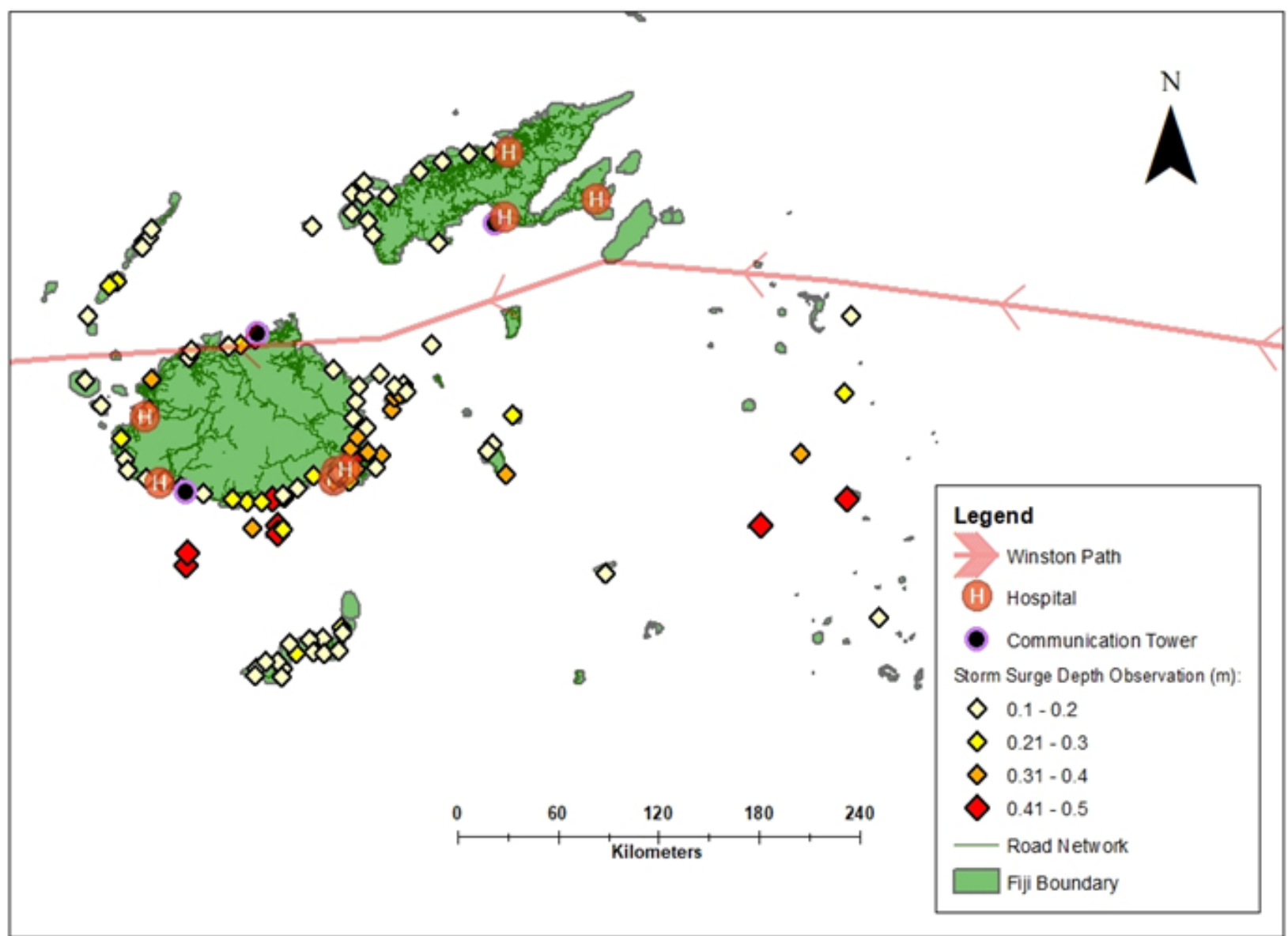

Figure 4: TC Winston path with storm surge observations and infrastructure.

Data sources include: Feature layer of Global Disaster Alert and Coordination System surge values (Global Disaster Alert and Coordination System, 2017) (Global Disaster Alert and Coordination System (GDAC) 2017). Locations of Fiji hospitals and communication towers downloaded from Open Street Map, 2016a and Open Street Map, 2016b (Open Street Map 2016b, a). Fiji road network data obtained from HDX (2019b, 2019c) (HDX 2019b, c, a). 


\section{c) Impact on the natural environment}

To assess the damage caused by TC Winston to the natural environment, its path was mapped in relation to a dataset containing local coral reefs and their threat level (World Resources Institute 2011). The results of this spatial analysis shown in Figure 5 demonstrate that after the sharp westward turn of the system, a great quantity of reefs was damaged. Within the most destructive path zone, over $65 \%$ of the coral reefs were at a high or very high threat level. This indicates that the event had a profound effect on the vulnerable coral species in Fiji, of which 17\% are under local protection (Government of Fiji 2016). The implications of this are significant, as coral reefs in this area are an important source of coastal protection against flooding and storm surges (Jacot Des Combes 2019). Therefore, it is likely that if another significant TC was to occur, the natural protective barrier on the coastline will be less effective due to the damage already induced by TC Winston.

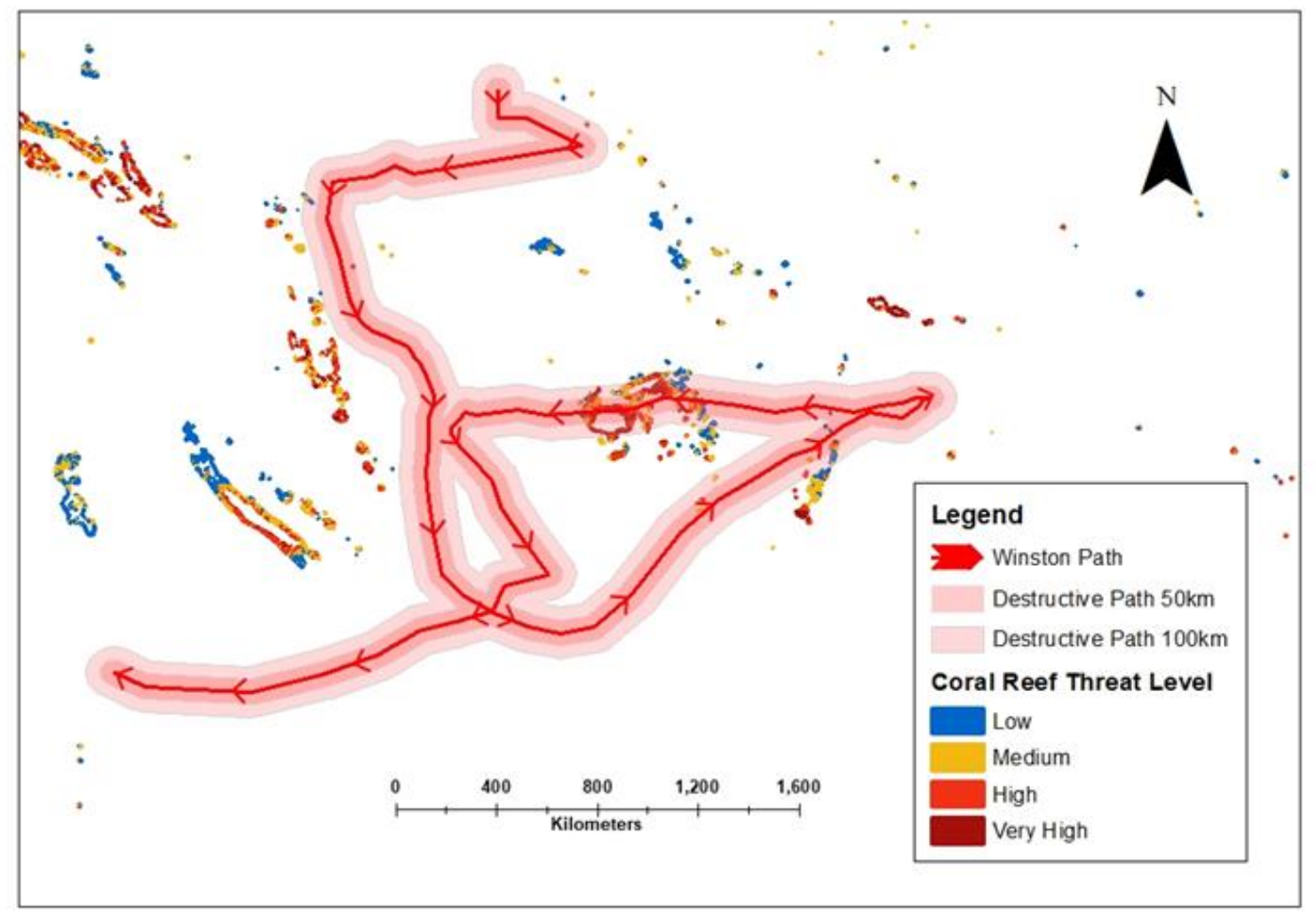

Figure 5: TC Winston path in relation to coral reefs classified by integrated local threat and past thermal stress.

ii. Moving forward-key considerations for Post Disaster Reviews

In summary, PDRs and impact assessments of TCs on population, infrastructure and natural environment in Fiji have demonstrated the potential scale of destruction to vulnerable nations in the tropics. PDRs are an integral component of a well-informed and evidence based DRR; they are essential to both the development and iteration of EWSs. Thus, PDRs should be regarded as a complimentary tool that can objectively examine disaster response and impacts in ways that policy makers and disaster managers can use in future scenarios to limit impacts on populations, infrastructure, and the natural environment. 


\section{Risk Assessments}

\section{i. Disaster risk knowledge}

In vulnerable communities, user-centered I-EWSs that are effective in terms of warning accuracy and appropriate output dissemination to key stakeholders, can inform improved management of disaster risk and climate extremes for increased community resilience. As discussed previously, an effective user-centered I-EWS consists of four interconnected components including risk knowledge, warning service, communication and dissemination, and response capability (de León et al. 2006). Each component is key to the overall efficiency of the IEWS (Kuleshov et al. 2019). If one component is lacking the entire system would not succeed in efficiently informing disaster risk management. The first component, risk knowledge, considers the patterns and trends in hazards and vulnerabilities that lead to risks (de León et al. 2006).

\section{ii. Disaster risk assessment}

Risk assessments including risk analysis and mapping are used to set priorities in I-EWS needs and guide response preparedness and risk management. Without effective development of risk assessments to increase disaster risk knowledge, an I-EWS cannot operate properly.

Past studies have investigated the potential for early warning informed risk management in vulnerable countries but tend to only touch on the risk analysis component of EWSs (Kuleshov et al. 2019; Webb 2020). The risk knowledge component of I-EWSs requires further investigation for more efficient implementation of future user-centered I-EWS (Mercer 2010).

\section{iii. Risk assessments for drought, floods and tropical cyclones}

Risk assessments could be vital to the efficiency of disaster risk management for natural hazards such as drought, floods, and tropical cyclones. However, risk knowledge for these disasters on a localized scale remains minimal (Kuleshov et al. 2019; Webb 2020). Risk assessments have been conducted for both slowonset hazards like drought and fast-onset hazards like floods and tropical cyclones in vulnerable communities around the world; however, these have been conducted on broad scales rather than tailored to local vulnerable communities. Tailoring risk assessments to more specific, local areas is important to accurately display risk levels so that vulnerable communities may plan for risk accordingly on a localized scale.

Although tailored drought risk assessments are novel, this report provides a proof-of-concept user-centered I-EWS for drought and forecast-based financing ( FbF) pilot study, which emphasize the value that a tailored risk assessment may have to proactive disaster management and early warning systems.

\section{Case Study-Northern Murray-Darling Basin, Queensland, Australia}

To develop a methodology for future conduction of tailored natural hazard risk assessments in local vulnerable communities as part of an I-EWS informing efficient DRR and climate adaptation, a case study was conducted for drought vulnerable areas in the Northern Murray-Darling Basin (MDB) in Australia (Aitkenhead 2020).

Historical records for the Northern MDB from the Australian Bureau of Meteorology show that the region frequently experiences severe drought conditions (Australian Bureau of Statistics (ABS) 1988). Due to its national economic value, the Northern MDB especially requires efficient drought management (Hart 2016). In 2017-2019, the Northern MDB was affected by severe drought, with record low rainfall in many parts of the region.

\section{i. Background}

Regions within the Northern MDB that are of particular interest include the Local Government Areas (LGAs) of Balonne Shire, the Goondiwindi Region, the Maranoa Region, Murweh Shire and Paroo Shire (Figure 6). Future drought events are expected to have significant impacts on the agriculture sector and functionality of communities within these LGAs (Quiggin et al. 2010). To manage the negative impacts of drought on local Northern MDB communities, key stakeholders, including state government officials, local farming association 
individuals, and local farmers have contributed to the implementation of three major Agricultural Drought Management Strategies (ADMSs): (i) the MDB Plan, (ii) Water Trading, and (iii) Government Assistance (resources and financial) (Docker and Robinson 2014). An accurate assessment of drought risk would inform stakeholders of the suitability of these drought management strategies (Yin et al. 2014). There has been no previous research on tailoring a holistic drought risk index to conduct drought risk mapping on a LGA level within the Northern MDB.

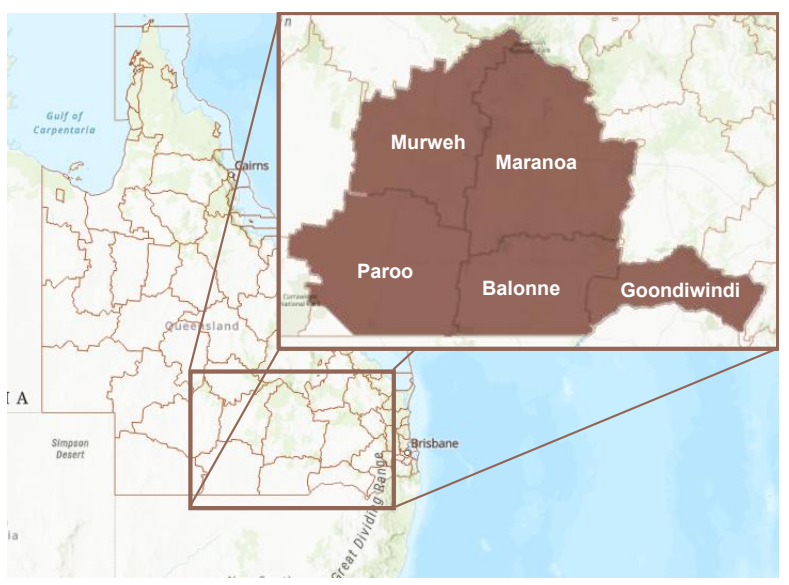

Figure 6: Spatial extent showing the five LGAs-Balonne Shire, Goondiwindi Region, Maranoa Region, Murweh Shire and Paroo Shire.

The development of a region-specific drought risk index and the accurate assessment of drought risk management strategies in Northern MDB LGAs would allow decision makers to observe where ADM resources are being appropriately allocated, and identify areas that require increased attention and provision of additional resources to enhance ADM resilience (Sena et al. 2017). In this case study, a region-specific drought risk index was developed to indicate drought risk extent of five Northern MDB LGAs, and current ADMSs implemented in these LGAs were assessed in terms of proactivity, effectiveness, and suitability. This allowed us to examine the potential for a user-centered I-EWS for drought to improve ADMSs in Northern MDB local farming communities.

\section{ii. Approach}

Hazard, vulnerability, and exposure indicators most applicable to drought risk assessment in five selected LGAs were determined by integrating information regarding the characteristics of the Northern MDB and analysis of similar approaches to indicator selection used in earlier studies. The WMO Handbook of Drought Indicators and Indices (Svoboda and Fuchs 2016) was used to confirm the extent of indicator feasibility and relevance. The selected indicators are listed in Table 1. These indicators were used to calculate Hazard, Vulnerability and Exposure indices which were then mapped and overlayed to produce Drought Risk Index maps.

Additionally, to assess the efficacy of ADMSs used in the region stakeholder surveys were designed by adapting a Criteria-Based Ranking (CBR) (Ho 2018). Officials and local farming association individuals ranked three major ADMSs used in the Northern MDB (the MDB Plan, Water Trading, and Government Assistance) by responding to a series of proactivity and effectiveness criteria statements (developed via analysis of earlier studies (Cobon et al. 2009; Williges et al. 2017; Dayal, Deo, and Apan 2018)).

\begin{tabular}{cl} 
Hazard & $\begin{array}{l}\text { Standardized Precipitation Index (SPI) } \\
\text { Vegetation Health Index (VHI) }\end{array}$ \\
\hline Vulnerability & $\begin{array}{l}\text { Agricultural occupation (\% of total population }>15 \text { in labor force) } \\
\text { Average household income (mean household income (AUD)) }\end{array}$ \\
\hline Exposure & Land use (type) \\
Average elevation $(\mathrm{m})$
\end{tabular}

Table 1: Selected Hazard, Vulnerability, and Exposure indicators 
iv. Results

This study revealed five key results:

1. Current (2020) drought hazard was shown as considerable for three of the five LGAs. All LGAs exhibited a high degree of current (2020) drought vulnerability, exposure and risk (Table 2).

2. All three major ADMS's used in the Northern MDB (MDB Plan, Water Trading and Government Assistance) were sub optimally proactive and effective. Government Assistance was overall ranked the most proactive and the most effective.

3. ADM suitability was 'Very Suitable' in the Maranoa Region and Murweh Shire, 'Not
Suitable' in the Goondiwindi Region, 'Slightly Suitable' in Balonne Shire, and 'Suitable' in Paroo Shire.

4. Two of the five LGAs investigated are of high priority for ADM review in the future: the Goondiwindi Region and Balonne Shire. Balonne Shire and the Goondiwindi Region were indicated to be at a very high risk to drought and rely on unsuitable ADMSs that lack proactivity.

5. All LGAs could consider the use of a usercentered I-EWS for drought, as it can improve the resilience of $\mathrm{ADM}$ in highly at-risk areas (Kuleshov et al. 2019).

6.

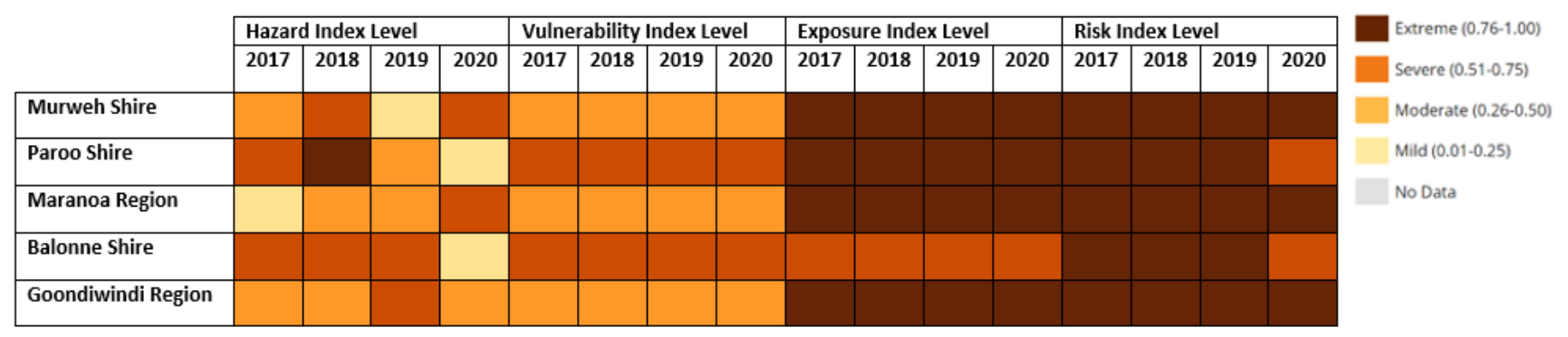

Table 2: Hazard, Vulnerability, Exposure and Risk Index Levels for each of the five LGAs investigated for 2017, 2018, 2019 and 2020 (from January to December in 2017-2019 and from January to July in 2020).

\section{iv. Moving forward}

Disaster risk management should focus on proactive and suitable strategies. Risk assessments are key for guiding stakeholders on the assessment of disaster risk management strategies and are vital for informing improvements upon currently existing strategies, particularly on the regional and local scales. As demonstrated in this case study, disaster risk assessments can identify specific areas which are of priority for increasingly resilient risk management. The Northern MDB case study methodology could be adapted for assessing risk on a multi-hazard scale in the context of other vulnerable communities around the world to increase global disaster risk knowledge for user-centered I-EWSs and guide risk management decisions. Investment in DRR and climate adaptation has increased on a global scale. However, improved understanding is required for the local scale to ensure community resilience in vulnerable countries (Mercer 2010). Disaster risk assessments can be vital in this effort.

\section{System}

Early Warning Systems (EWSs) are structures used to predict, monitor, and manage disasters across the world (United Nations Development Programme (UNDP) 2018). Such systems, when applied in a usercentered manner, have significant potential to aid proactive decision-making. They are complex, adaptive systems comprised of four fundamental components (World Meteorological Organization (WMO) 2018, Kelman and Glantz 2014):

1. Risk knowledge-identification of the worst impacts and threats including a consolidated assessment of any exposures and vulnerabilities

2. Monitoring and warning-the infrastructure that detects climate variabilities in the lead up to disaster with a sound technical and scientific basis

3. Communication and dissemination-the communications frameworks that ensures early warnings are delivered efficiently to vulnerable groups 
4. Response capability-the centralized systems and knowledge that enable communities to effectively respond to early warnings

An EWS that is user-centered and integrated has the potential to save lives, limit physical damage, and lessen financial losses (Merz et al. 2020).

\section{i. Linear versus Interconnected}

Historical early warning literature often presents EWS components as a subset of a 'linear chain' or an end-to-end (Baudoin et al. 2016) model. The components tend to be viewed in isolation from each other (World Meteorological Organization (WMO) 2018), with little explanation of their linkages and dependencies (Figure 7 - from (Bhardwaj 2020)) and often with a single-minded focus on the technical monitoring and warning component (Garcia and Fearnley 2012).
This approach was extensively critiqued in the devastating aftermath of the December 2004 tsunami in the Indian Ocean which highlighted the failure of several social factors within tsunami EWSs at the time (Marchezini et al. 2017). As a result, contemporary approaches emphasize the importance of interconnected systems; accepting that EWSs "are only as effective as their weakest link" (United Nations Development Programme (UNDP) 2018). Figure 8 illustrates the linkages that a more interwoven model would address (from (Bhardwaj 2020)). Grey arrows indicate direct linkages and purple arrows indicate community-informed iteration. This interwoven model still emphasizes the importance of robust technical capabilities but is able to adapt these capabilities in the context of the community it services (Garcia and Fearnley 2012; Baudoin et al. 2016).

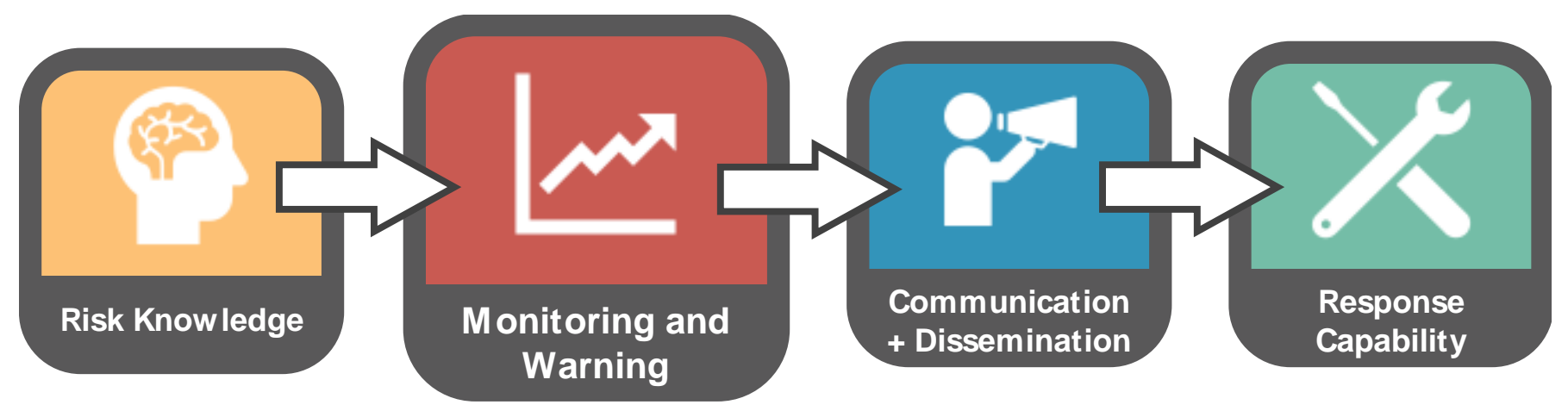

Figure 7: Linear, End to End model

\section{ii. User-centered and integrated}

The interwoven model demonstrates that the utility of such systems is ultimately dependent on their ability to service their nuanced users as well as their broader structural construction as a system integrated into a broader landscape of meteorological decision-making tools.

\section{User-centered}

Natural hazards and disasters have far-reaching impacts that touch on all elements of human life. Thus, for an EWS to be a strong, interconnected system that doesn't consider warning delivery to be linear or end-to-end, there needs to be a substantial focus on the users of the system (Macherera and Chimbari 2016; Garcia Londoño 2011). In this way the focus on user-informed iteration and development is just as vital to the success of the system as its accuracy in the early prediction of natural hazards and is accordingly reinforced in the titling of EWSs referenced throughout this report (Baudoin et al. 2016; World Meteorological Organization (WMO) 2018).

\section{Inclusion of indigenous perspectives}

The inclusion of diverse and representative perspectives in the decision-making process is imperative in ensuring that early warning climate information is timely, usable, and adaptive (Macherera and Chimbari 2016; Andersson et al. 2019). Indigenous Peoples have long used traditional knowledge to monitor and predict weather conditions in their local environments through use of sophisticated forecasting frameworks that holistically combine elements of modern-day astronomy, meteorology, and ecology (Kelman, Mercer, and Gaillard 2012; Mercer et al. 2007). Such knowledge is contextual, adaptive, and trusted by 
local communities and has the potential to increase early warning uptake and actionability in communities where technical information and western knowledge may not be as transferable and trusted (Mercer et al. 2007; Andersson et al. 2019). Thus, the inclusion of such diverse perspectives needs to be considered at each stage of an EWS (Kelman, Mercer, and Gaillard 2012).

\section{Integrated}

A user-centered EWS alone may be futile in its construction if there is no consideration for the structural implementation of the system as one that is either centralized, decentralized, or integrated. In this context, a centralized EWS is one that operates on a federal or state level (Baudoin et al. 2016) and interacts coarsely with a national audience. Whereas a decentralized system operates on a finer scale with a more localized audience and tends to roll out warnings through established trust networks (Baudoin et al. 2016). Centralized systems provide invaluable information on a coarse scale to government officials and management agencies. However, they are not so efficient in disseminating actionable, granular information to small scale farmers, regional communities, and the individuals most at risk (Andersson et al. 2019; Baudoin et al. 2016; Basher 2006; Garcia and Fearnley 2012).

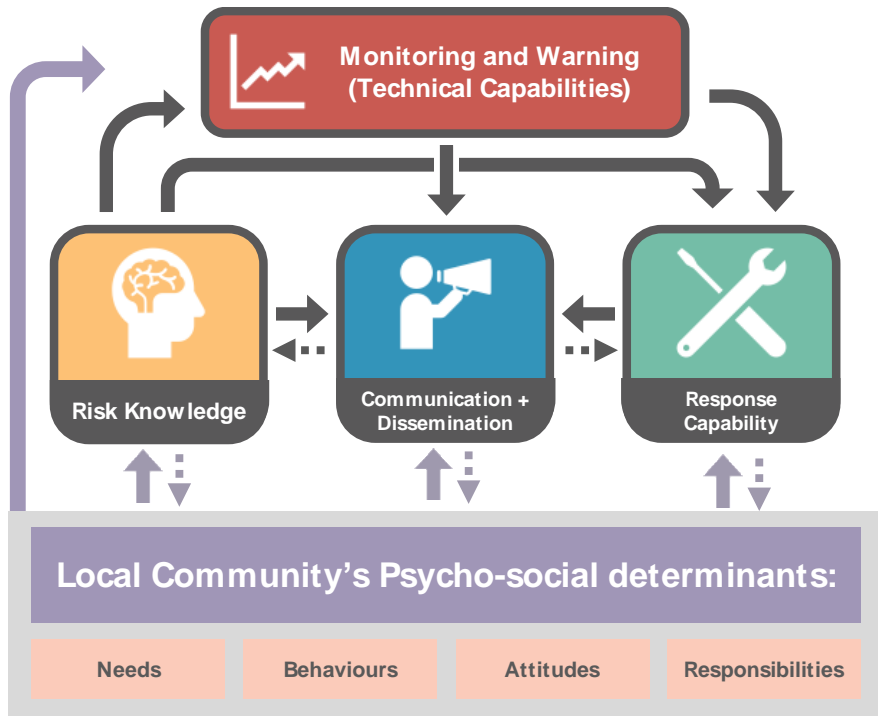

Figure 8: Interwoven model where grey arrows indicate direct linkages and purple arrows indicate community.

\begin{tabular}{|c|c|c|c|}
\hline Characteristic & Centralized EWSs & Decentralized EWSs & Integrated EWSs \\
\hline Approach & $\begin{array}{l}\text { "Top-down" or "last mile" } \\
\text { Linear or E2E }\end{array}$ & $\begin{array}{l}\text { "Bottom-Up" or "First-mile" } \\
\text { Interwoven }\end{array}$ & $\begin{array}{l}\text { Stakeholder-informed and } \\
\text { interwoven in design }\end{array}$ \\
\hline Focus & Hazard focused & Community focused & Holistic focus \\
\hline Participation & Low & High & High \\
\hline Capabilities & Highly technical & Limited technical capabilities & Mixed \\
\hline Monitoring & $\begin{array}{c}\text { Automatic (e.g., remote } \\
\text { sensing) }\end{array}$ & $\begin{array}{c}\text { Manual (e.g., surface-based } \\
\text { observations) }\end{array}$ & Combination (data blending) \\
\hline Forecasting & Complex and probabilistic & $\begin{array}{c}\text { Based on } \\
\text { traditional/indigenous } \\
\text { knowledge }\end{array}$ & Mixed \\
\hline Communication & $\begin{array}{l}\text { General and on a coarse } \\
\text { scale (sometimes with a lot } \\
\text { of technical language) }\end{array}$ & $\begin{array}{l}\text { Region-specific and in the } \\
\text { language of the locals } \\
\text { (endorsed by trusted figures) }\end{array}$ & $\begin{array}{l}\text { Region specific, impact-based } \\
\text { and easy to understand by } \\
\text { local users }\end{array}$ \\
\hline $\begin{array}{l}\text { Emergency } \\
\text { Response }\end{array}$ & Initiated by government & Initiated by individuals & Combination \\
\hline
\end{tabular}

Table 3: Centralized, decentralized, and integrated EWS summary 
Decentralized systems tend to do this well and have been found to generate extensive community involvement and trust in the system; however, technical infrastructure for such systems is usually poor. In this way, an integrated EWS combines strengths of both decentralized and centralized EWSs, thus minimizing the weaknesses resultant of utilizing one structural approach in isolation. A summary of the key characteristics of centralized, decentralized and integrated EWSs is presented in Table $\mathbf{3}$ (Bhardwaj 2020) adapted from (Garcia and Fearnley 2012) and (Macherera and Chimbari 2016).

Thus, integrated EWS is best conceptualized as a system that is supported and sustained by a national meteorological service but is controlled and managed on a local scale: likely through a diverse extension network that is comprised of both climate experts and local stakeholders (Garcia Londoño 2011). For an integrated EWS to be successful, clear roles and responsibilities for each level of management involved would need to be defined and Standard Operating Procedures (SOPs) would need to be created. An iterative system like this would also be open to adjustment through dynamic feedback loops that minimize bureaucracy at all possible stages and prioritize community feedback (Macherera and Chimbari 2016).

The methodologies used to construct an adaptive system like this would need to be equally adaptive. It would involve combining elements of both quantitative (i.e. defining system decision rules and thresholds and rigorous error testing) and qualitative research methods (i.e. understanding the psychosocial nuances of the community the EWS would service) (Baudoin et al. 2016; United Nations Development Programme (UNDP) 2018).

\section{Drought EWS case study}

A case study into the proof-of-concept construction for a user-centered I-EWS for drought was conducted

\section{Background}

Drought periods are estimated to cost the Australian economy in excess of AUD 1 billion per year (Hughes, Galeanol, and Hatfield-Dodds 2019). These impacts are further exacerbated for drought-vulnerable regions like the MDB. Examining drought management strategies in this region, we found that drought management within the Northern MDB is currently largely reactive. It was also found that drought support would benefit from greater consistency and planning, and a user-centered I-EWS for drought could aid with this (Wilhite, Sivakumar, and Pulwarty 2014).

\section{Approach}

In order to increase drought preparedness and resilience for farming communities in the Northern MDB, we constructed a user-centered I-EWS for drought using both quantitative and qualitative measures. The meteorological progression of drought was analyzed in order to determine indicators that may be suitable for early detection. Stakeholder interviews with primary producers were then used to gain insight into the definitions of drought most relevant to users as well as key communication and dissemination bottlenecks that an I-EWS in this region would have to account for.

\section{Results}

The constructed I-EWS was found to sufficiently detect periods of drought with an early warning lead time of three to eight months (Aitkenhead, Asghari, and Bhardwaj 2020; Bhardwaj 2020). Additionally, staged warning categories of "WATCH", "ALERT" and "DECLARATION" were triggered at various points in the study period (Figure 9). Detailed maps of the early warning status for each month in the study period were also generated. The most notable progression being depicted in 2019 when the region experienced a rapid intensification of dry conditions so extreme that this event has recently been termed a 'flash drought' (similar in its rapid development to a flash-flood event). This rapid intensification peaked in September 2019 and saw the MDB experiencing very high temperatures and hence evaporation, further depleting moisture from the landscape. This resulted in the lowest rainfall on record for the 22 months between October 2018 and January 2019 for the MDB (Bureau of Meteorology (BoM) 2020). This intensification of dry conditions was detected exceptionally well by the constructed I-EWS used for this study (see the phased progression from "WATCH" to "ALERT" to "DECLARATION" for 2019 in Figure 9.

The intensive drought case study provides insight into the approaches required to build similar proactive EWSs and can be adapted accordingly for 
the other hazards included in this report-floods and tropical cyclones. Figure $\mathbf{1 0}$ illustrates the methodology required for the construction of such systems, adapted from (Garcia Londoño 2011). It provides a holistic overview of the general process required to construct a user-centered I-EWS. A comprehensive task list that details all relevant tasks required to plan, develop and implement all four components of an EWS is presented in Appendix 1.

In accordance with this methodology, the CREWS team has been working alongside several organizations and national meteorological services to build capacity for a user-centered I-EWS for drought in Papua New Guinea (PNG) where different provinces in the country experience different degrees of dry conditions in times of El Niño and La Niña.

In 2015, PNG experienced severe drought caused by a strong El Niño. This drought resulted in prolonged frosts and periods of little to no rain which caused many subsistence crops to fail. Approximately 2.4 million people ( $40 \%$ of the PNG population) were affected with many perishing from famine conditions (Jacka 2020). A similar analysis to the Northern MDB case study was conducted for PNG and it was found that early warning would have been possible with a three-to-five-month lead time.

Similarly, between October 2020 and March 2021 a La Niña developed over the Pacific Ocean which led to dry conditions in PNG's northern provinces. Using the EWS utility built from the previous case study, the research team monitored the WATCH-ALERTDECLARATION status of each province in PNG and liaised with the PNG National Weather Service to indicate provinces that were deemed to be of concern. The results of both La Niña and El Niño analyses for PNG demonstrate value of the developed methodology and its application to designing a usercentered I-EWS for drought in the most vulnerable communities of LDCs and SIDS.

\section{iv. Moving forward}

It is evident that user-centered I-EWSs are a critical climate adaptation strategy that is pivotal to the longterm climate adaption of disaster-vulnerable regions. However, these systems need to be open to iteration and seamlessly integrated with the other climate adaptation strategies discussed throughout this report. Ultimately, I-EWSs are only as 'strong as their weakest link', thus, policy makers need to aspire to strengthen and develop I-EWSs that are embedded within deeper, structural climate adaptation strategies.

\section{Forecast-based Financing}

Forecast-based Financing (FbF) is a relatively new action-based DRR strategy that initiates anticipatory actions during the "window of opportunity" between a climate warning and a potential disaster (Coughlan de Perez et al. 2015). When forecast thresholds for a natural hazard are exceeded, FbF projects can disburse the necessary funds to implement predetermined early actions and thus prepare vulnerable communities (Coughlan de Perez et al. 2015).

\section{FbF Early Action Protocol}

$\mathrm{FbF}$ is a complex system requiring multi-agency engagement and therefore it is critical to document and outline processes within the system. Prior to a FbF project being implemented, stakeholders must collaborate and write up an Early Action Protocol (EAP) for the region of interest. This section outlines the responsibilities of all stakeholders under three key criteria:

1. Climate triggers-maximum thresholds for climate information are created, called triggers, such that when these thresholds are exceeded, early actions are automatically initiated. The proof-of-concept EWS provides exemplary trigger points for staged warning levels of "WATCH", "ALERT" and "DECLARATION".

2. Early actions-predetermined actions are selected to enable greater preparedness for community members. When predetermined climate triggers are activated, early actions are initiated to deliver assistance to the most vulnerable communities. These actions are determined through extensive engagement with local stakeholders, taking into consideration the lead times and the probability of the disaster event occurring.

3. Financing mechanisms - a dedicated fund is created for use so that when climate thresholds are exceeded, the funds can be disbursed immediately to deliver early action. Contrary to traditional humanitarian aid efforts, FbF projects require funds to be acquired before a hazard becomes a disaster to enable timely actions that increase preparedness. Once this EAP has been approved for a region, standard operating 
procedures are created to outline detailed information on the early actions to be implemented based on climate triggers.

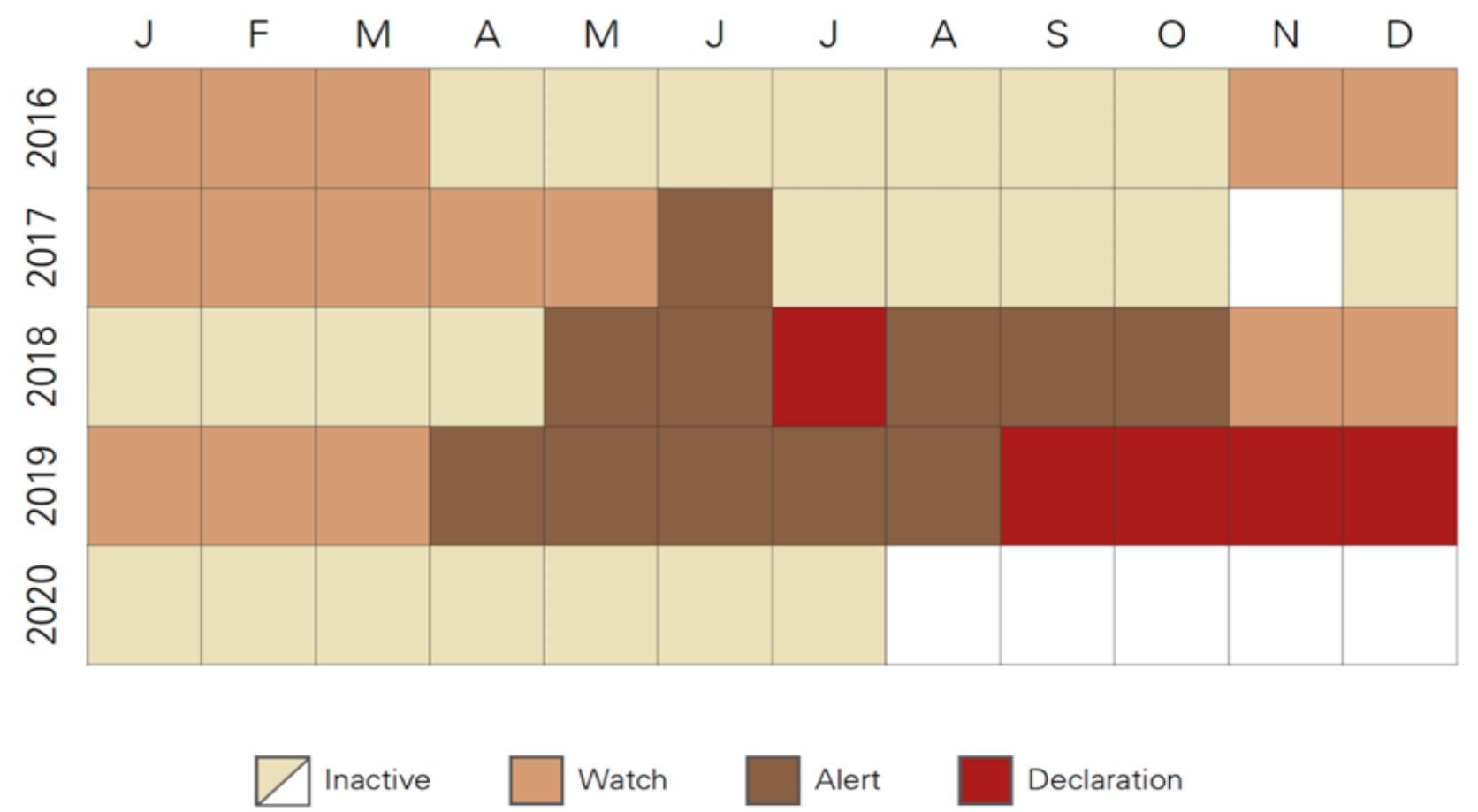

Figure 9: Overview of the user-centered I-EWS status for each month in the study period.

\begin{tabular}{|c|c|c|c|}
\hline $\begin{array}{l}\text { - Form local EWS } \\
\text { committees } \\
\text { - Estimate resources } \\
\text { required } \\
\text { - Conduct cost-benefit } \\
\text { analyses to bolster } \\
\text { political support } \\
\text { - Analyse existing } \\
\text { disaster management } \\
\text { framework } \\
\text { - Engage stakeholders }\end{array}$ & $\begin{array}{l}\text { - Create basic plan to } \\
\text { implement EWS } \\
\text { - Undertake Risk } \\
\text { Assessment } \\
\text { - Develop EWS proof of } \\
\text { concept and seek } \\
\text { feedback } \\
\text { - Conduct error testing } \\
\text { on EWS where possible } \\
\text { - Determine warning } \\
\text { dissemination methods }\end{array}$ & $\begin{array}{l}\text { - Activate EWS for } \\
\text { public use } \\
\text { - Ensure warnings are } \\
\text { trusted, credible and } \\
\text { actionable } \\
\text { - Organize educational } \\
\text { campaigns } \\
\text { - Train volunteers and } \\
\text { extension officers } \\
\text { - Perform drills and } \\
\text { simulations }\end{array}$ & $\begin{array}{l}\text { - Conduct post } \\
\text { disaster review } \\
\text { - Gather feedback } \\
\text { from stakeholders } \\
\text { and community } \\
\text { - Iterate EWS }\end{array}$ \\
\hline
\end{tabular}

Figure 10: Overview of the process required to construct a user-centered I-EWS for other natural hazards.

FbF for drought

There have been no $\mathrm{FbF}$ pilots for slow-onset disasters such as drought, in comparison to fast-onset disasters such as floods and tropical cyclones. This is due to a range of complexities associated with drought. Nonetheless, there is a need to implement proactive, resilience-building DRR approaches for drought, with multiple Red Cross national societies 
already beginning to develop EAPs for drought to address this need (Heinrich and Bailey 2020).

A study by Asghari investigated the feasibility of a FbF drought system to encourage proactivity within farmers in a market economy such as Australia (Asghari 2020). It was found that in its traditional form, FbF would not be suitable for Australia as direct forms of assistance may not encourage farm operators to regularly assess and adapt their drought management strategies (Asghari 2020; Productivity Commission 2005, 2009). Nonetheless, FbF has demonstrated positive outcomes in developing and least-developed nations where vulnerable populations may not be able to implement effective adaptation strategies independently.

Whilst FbF for drought is complex, this report provides a strategy for a drought risk assessment as well as a proof-of-concept user-centered I-EWS for drought that can greatly aid the development process.
Complexities of an FbF drought pilot

FbF projects are essentially about taking early actions to reduce the detrimental impacts of a disaster. Whilst this process is more complex for drought, it is helpful to be aware of potential challenges and mitigate against them. Table 4 outlines potential mitigation strategies in the development of a $\mathrm{FbF}$ system for drought that may be implemented to address a list of complexities that have been summarized from Heinrich and Bailey (2020).

\section{FbF for floods and tropical cyclones}

Numerous FbF systems have been implemented for fast-onset disasters such as floods and tropical cyclones. The following section summarizes case studies from Bangladesh and the Philippines.

\begin{tabular}{|c|c|}
\hline Drought complexities & Mitigation strategies \\
\hline No clear start or end dates & $\begin{array}{l}\text { Select region-specific thresholds and triggers that have been } \\
\text { proven to be useful in the past }\end{array}$ \\
\hline $\begin{array}{l}\text { Long lead times (months) that make } \\
\text { it difficult to determine suitable } \\
\text { early actions }\end{array}$ & $\begin{array}{l}\text { Incorporate a staged EWS into the trigger systems and implement } \\
\text { early actions relevant to the different categories }\end{array}$ \\
\hline Impacts of drought vary by group & $\begin{array}{l}\text { Create different EAPs for various vulnerable groups (e.g., farmers, } \\
\text { local business owners, etc.) }\end{array}$ \\
\hline Wider geographic scope & $\begin{array}{l}\text { Utilizing thorough risk assessments to determine the most } \\
\text { vulnerable populations }\end{array}$ \\
\hline $\begin{array}{l}\text { Wide variety of actors engaged in } \\
\text { drought preparedness }\end{array}$ & $\begin{array}{l}\text { Clear outlines of the roles and responsibilities of all actors and } \\
\text { consistent communication and collaboration }\end{array}$ \\
\hline
\end{tabular}

Table 4: Mitigation strategies for the implementation of FbF drought pilots

\section{Flood case study-Bangladesh}

In 2019 the International Federation of Red Cross and Red Crescent Societies (IFRC) Disaster Relief Emergency Fund approved a flood EAP for the Jamuna river system in Bangladesh, set to be active for five years. The following information has been summarized from the EAP submitted by the Bangladesh Red Crescent Society (Bangladesh Red Crescent Society 2019).

\section{i. Country context}

Bangladesh is one of the most flood-prone countries globally due to its location and land characteristics, particularly as the country is low-lying, flat, and has large inland water bodies (Brouwer et al. 2007). Risk analyses indicates that approximately one third of Bangladesh could be severely impacted by floods once every ten years, resulting in extreme social disruptions, damage to infrastructure, and economic loss (Brouwer et al. 2007). Vulnerable groups are those living in low-lying areas, in fragile housing, with multiple dependent family members and experiencing poverty. In 1998, Bangladesh experienced a devastating flood, resulting in 
approximately 1,000 deaths, 30 million people displaced from their homes, significant crop and livestock damage, and a high outbreak of waterborne disease. It is estimated that the government experienced a total economic loss of approximately USD 2 billion (Bangladesh Red Crescent Society 2019).

\section{ii. EAP aims}

The flood EAP for Bangladesh addresses three impacts:

1. Human casualty.

2. Loss of household assets and food grains.

3. Loss of livelihood linked to livestock. iii. Climate triggers

This EAP uses a global forecast model- the Global Flood Awareness System (GLOFAS)- for preactivation as well as the Flood Forecasting and Warning Centre's deterministic model for activation of early actions. Probabilistic flood forecasts are issued with a 15-day and 10-day lead time.

\section{iv. Early actions}

The following early actions are implemented once the climate triggers have been activated:

i. Dissemination of awareness-raising messages and evacuation to reduce the human casualty (deaths due to drowning and others).

ii. Distribution of unconditional cash grant $(4,500$ Taka per household) to reduce the loss of household assets, food grains and livelihoods.

\section{Tropical cyclone case study-Philippines}

In 2019 the IFRC approved a tropical cyclone EAP for the Philippines. The following information has been summarized from the EAP submitted by the Philippine Red Cross (Philippine Red Cross 2019).

\section{i. Country context}

The Philippines is considered a highly disaster-prone country, with the impacts of tropical cyclones in particular found to demonstrate a consistently increasing trend in economic losses and damages (Cinco et al. 2016). In 2013, the Philippines experienced Typhoon Haiyan (Yolanda), and despite warnings two days in advance, appropriate preparatory actions were not taken (Lagmay et al. 2015).

\section{ii. EAP aims}

The EAP for this project aims to address the following impacts:

1. The loss of income of rice/corn/abaca farmers and municipal fisherfolk

2. The damages to houses

\section{iii. Climate triggers}

An impact forecast model, developed by the Netherlands Red Cross, was determined as the most suitable mechanism to create triggers. This model allows for a lead time of 3 days, as well as providing a vulnerability index to determine the most vulnerable municipalities, predicted to incur the highest damage.

\section{iv. Early actions}

Three primary early actions were defined by the Philippines Red Cross and are summarized in Table 5 below. 


\section{Early Action Tasks to be undertaken prior to triggering of early action}

Strengthening of shelters

Livestock evacuation
Pre-procure part of the Shelter Strengthening Kits (nylon ropes, nails, tie wire, and iron rebar cleats). This kit is to be kept in warehouses in each target area. Once an activation of the early action is confirmed, further supplies are acquired and delivered to target areas.

Early harvest of crops

Safe storage facility for harvested crops identified for target areas, harvesters are identified, and transportation for crops is determined.

Safe evacuation areas are determined, a team is created to undertake this task, the transport suppliers are identified, and onsite materials are prepared to care for livestock.
Table 5: Philippines Red Cross Early Actions summary

These case studies demonstrate that $\mathrm{FbF}$ is a wellestablished system with significant capacity to build resilience within vulnerable communities in the face of multiple disasters. The process can have widespread application, with extensive local stakeholder engagement ensuring that programs are adapted to local conditions and needs.

\section{v. Moving forward}

FbF projects have been implemented worldwide and consequently, lessons have been learned. In future $\mathrm{FbF}$ projects, the following must be taken into consideration:

- Intensive community engagement must occur to determine suitable early actions.

- The system must rely on evidence-based forecasts to service vulnerable groups and be in the best interest of the community.

- FbF pilot projects for drought need to be established and advanced initially on a small scale in selected SIDS and LDCs, then, if suitable, scaled up to broader regional FbF programs.

- There must be coordination between agencies, such as NGOs, acting within the same region.

- In assessing vulnerability and risk, consideration must be made for groups that may not have been included in the databases used for such assessments.

- Expertise in systems, procedures, and financial management must be present to assist in avoiding malpractice and corruption within the FbF programs.
Ultimately, FbF projects are an effective means to initiate early action during the period between a warning and a disaster. By establishing early actions for the most vulnerable communities, FbF allows for significant loss to be mitigated and builds a culture of proactivity.

\section{Key recommendations for policy makers}

We have amalgamated the various individual insights from each specific climate adaptation strategy discussed in this report into broader recommendations that are targeted towards policy makers who manage disaster risk at all levels: from Federal to State to provincial scales.

This is because these recommendations are likely to fall under a variety of jurisdictions and thus require the careful consideration and collaboration of all levels of management.

1. No DRR strategy can be delivered from "on high" (direct participant quote-(Aitkenhead, Asghari, and Bhardwaj 2020). Policy makers need to consider the structural approach of their implemented strategy and utilize elements of both top-down and bottom-up approaches. This means allowing time and resources for significant community consultation.

2. PDRs conducted at all policy levels need to focus on impacts experienced by the community in order to accurately reflect to policy makers the costs of inaction on vulnerable communities under their leadership (Hidayat and Egbu 2010). 
3. Risk assessments should be implemented at the local to regional level in order to efficiently allocate resources. This will highlight to state and national-level policy makers the regions requiring most urgent action. Local to regional implementation of risk assessments also ensures that risk assessments incorporate nuance that would otherwise be lost at state and federal levels (Wamsler and Lawson 2012).

4. Policy makers should note the methodological replicability for user-centered I-EWSs discussed in this report. Space-based observations are readily available for most countries and provide value for SIDS and LDCs where surface-based monitoring infrastructure may be limited. These inputs paired with forecasting models have the potential to provide significant early warning for local communities (Andersson et al. 2019).

5. There needs to be significant collaboration between national and state level policy makers and the relevant NGOs and agencies that seek to implement FbF programs. Policy makers should pay particular attention towards explicitly highlighting how such programs compliment. (Coughlan de Perez et al. 2016)

\section{Concluding remarks}

This report discussed four proactive, localized, and inclusive adaptation strategies to address the impacts of drought, floods, and tropical cyclones for the most vulnerable communities.

Each strategy outlined in this report plays a vital role in addressing the needs of vulnerable populations to minimize loss and devastating impacts for future disasters and must be considered collaboratively rather than in isolation. Numerous stakeholders, agencies, and governments are involved throughout this process and thus clear, consistent protocols must be established.

Without such proactive and decisive action now, disaster-prone regions across the world will continue to cycle through periods of insufferable damage with limited recovery. Thus, the immediate implementation of proactive, localized, and inclusive approaches to natural hazards will work to lessen the detriments of future disasters and further safeguard some of the most vulnerable communities across the world. 


\section{Appendix}

This table provides a comprehensive list of all required tasks that need to be completed for the successful implementation of a user-centered I-EWS for the three natural hazards covered in this report. It is primarily adapted off (Garcia Londoño 2011) with further inclusions from (Abarquez and Murshed 2004; Basher 2006; Mileti and Sorensen 1990; United Nations Development Programme (UNDP) 2018; World Meteorological Organization (WMO) 2018)

\begin{tabular}{|c|c|c|}
\hline $\begin{array}{l}\text { EWS } \\
\text { Compo } \\
\text { nent }\end{array}$ & $\begin{array}{l}\text { Sub- } \\
\text { Component }\end{array}$ & Key Tasks \\
\hline \multirow{9}{*}{ 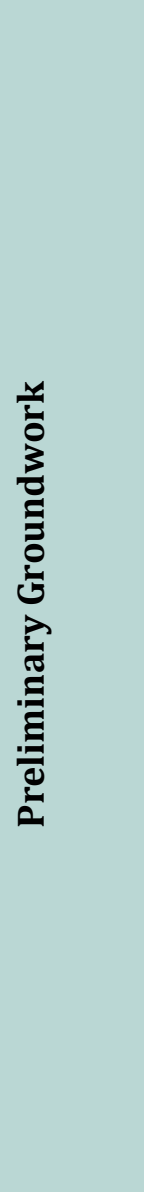 } & \multirow[t]{3}{*}{$\begin{array}{l}\text { Institutional } \\
\text { Context }\end{array}$} & $\begin{array}{l}\text { Analyze legal and policy frameworks for scope to introduce EWS as a DRR } \\
\text { tool within the region required }\end{array}$ \\
\hline & & $\begin{array}{l}\text { Determine how an EWS would be integrated into existing centralized and } \\
\text { decentralized DRR and emergency frameworks }\end{array}$ \\
\hline & & $\begin{array}{l}\text { Estimate resources required and secure funding mechanism for EWS (cost- } \\
\text { benefit analyses of economic and human damage lessened with an EWS may } \\
\text { help bolster political support) }\end{array}$ \\
\hline & \multirow{2}{*}{$\begin{array}{l}\text { Stakeholder } \\
\text { Roles and } \\
\text { Responsibilities }\end{array}$} & $\begin{array}{l}\text { Identify all stakeholders and organizations involved and develop local EWS } \\
\text { committee or task force with representatives from all stakeholder groups }\end{array}$ \\
\hline & & $\begin{array}{l}\text { Define stakeholder and organization responsibilities for each EWS stage- } \\
\text { select specific coordinators if possible }\end{array}$ \\
\hline & \multirow{3}{*}{$\begin{array}{l}\text { Development of } \\
\text { platforms, } \\
\text { documents and } \\
\text { materials }\end{array}$} & $\begin{array}{l}\text { Establish platform/s to share data, communication and correspondence } \\
\text { within EWS stakeholders and actors. }\end{array}$ \\
\hline & & $\begin{array}{l}\text { Develop user-engagement materials to engage vulnerable community } \\
\text { members in the development of the user-centered EWS (surveys, semi- } \\
\text { structured interviews, etc.) }\end{array}$ \\
\hline & & Develop SOPs for how to engage users and individuals \\
\hline & $\begin{array}{l}\text { Understand } \\
\text { community } \\
\text { needs }\end{array}$ & $\begin{array}{l}\text { Conduct needs assessments to understand community responses, attitudes } \\
\text { and behaviors that can be used to streamline the construction of all four } \\
\text { EWS elements }\end{array}$ \\
\hline
\end{tabular}




\begin{tabular}{|c|c|c|}
\hline \multirow{15}{*}{ 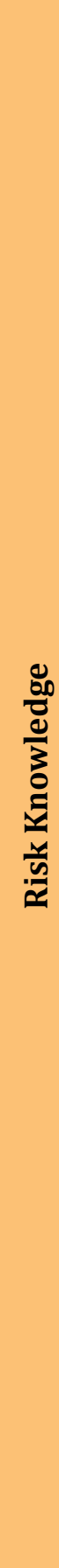 } & \multirow[t]{3}{*}{$\begin{array}{c}\text { Hazard } \\
\text { Assessment }\end{array}$} & $\begin{array}{l}\text { Conduct hazard mapping using appropriate indicators-include hazards } \\
\text { maps from past time periods to provide context for changing hazard levels }\end{array}$ \\
\hline & & $\begin{array}{l}\text { Identify hazard causes and triggering factors (using both scientific and local } \\
\text { knowledge). }\end{array}$ \\
\hline & & Ensure outputted hazard maps are readily accessible by all stakeholders. \\
\hline & \multirow{4}{*}{$\begin{array}{l}\text { Vulnerabilities } \\
\text { and Exposures } \\
\text { Assessment }\end{array}$} & $\begin{array}{l}\text { Consider a diverse range of vulnerability and exposure indicators (i.e. social, } \\
\text { physical, structural, political, economic and environmental) }\end{array}$ \\
\hline & & $\begin{array}{l}\text { Capture vulnerability and exposure assessment data using combinations of } \\
\text { quantitative (i.e. dataset analysis) and qualitative methods (i.e. } \\
\text { participatory surveys) }\end{array}$ \\
\hline & & Assess and quantify exposed people, services and critical infrastructure \\
\hline & & $\begin{array}{l}\text { Identify local patterns of vulnerability (including links between causes, } \\
\text { dynamic pressures and unsafe conditions) }\end{array}$ \\
\hline & \multirow[t]{5}{*}{$\begin{array}{l}\text { Risk } \\
\text { Assessment }\end{array}$} & $\begin{array}{l}\text { Develop standardized methodology (with a sound scientific basis) for risk } \\
\text { assessments and mapping at local, state and national levels. }\end{array}$ \\
\hline & & Integrate both historical and indigenous knowledge into risk assessments \\
\hline & & $\begin{array}{l}\text { Review and update risk assessment information at timescales appropriate } \\
\text { to the natural hazard/disaster in focus. }\end{array}$ \\
\hline & & $\begin{array}{l}\text { Integrate risk assessment results into local emergency plans-in situations } \\
\text { where funding is limited risk assessments may also be used to determine } \\
\text { regions that need prioritized implementation of EWS and DRR strategies. }\end{array}$ \\
\hline & & Use risk information to identify and define evacuation routes and locations \\
\hline & \multirow[t]{3}{*}{$\begin{array}{l}\text { Data and Map } \\
\text { Availability }\end{array}$} & $\begin{array}{l}\text { Establish a central repository for GIS data and all hazard, vulnerability and } \\
\text { exposure information so that it is readily accessible by all stakeholders. }\end{array}$ \\
\hline & & $\begin{array}{l}\text { Develop standards (where possible following best-practice, international } \\
\text { standards) for the systematic collection and collaboration of all risk } \\
\text { information. }\end{array}$ \\
\hline & & $\begin{array}{l}\text { Consider making all hazard, vulnerability, exposure and risk data and maps } \\
\text { publicly available. }\end{array}$ \\
\hline
\end{tabular}




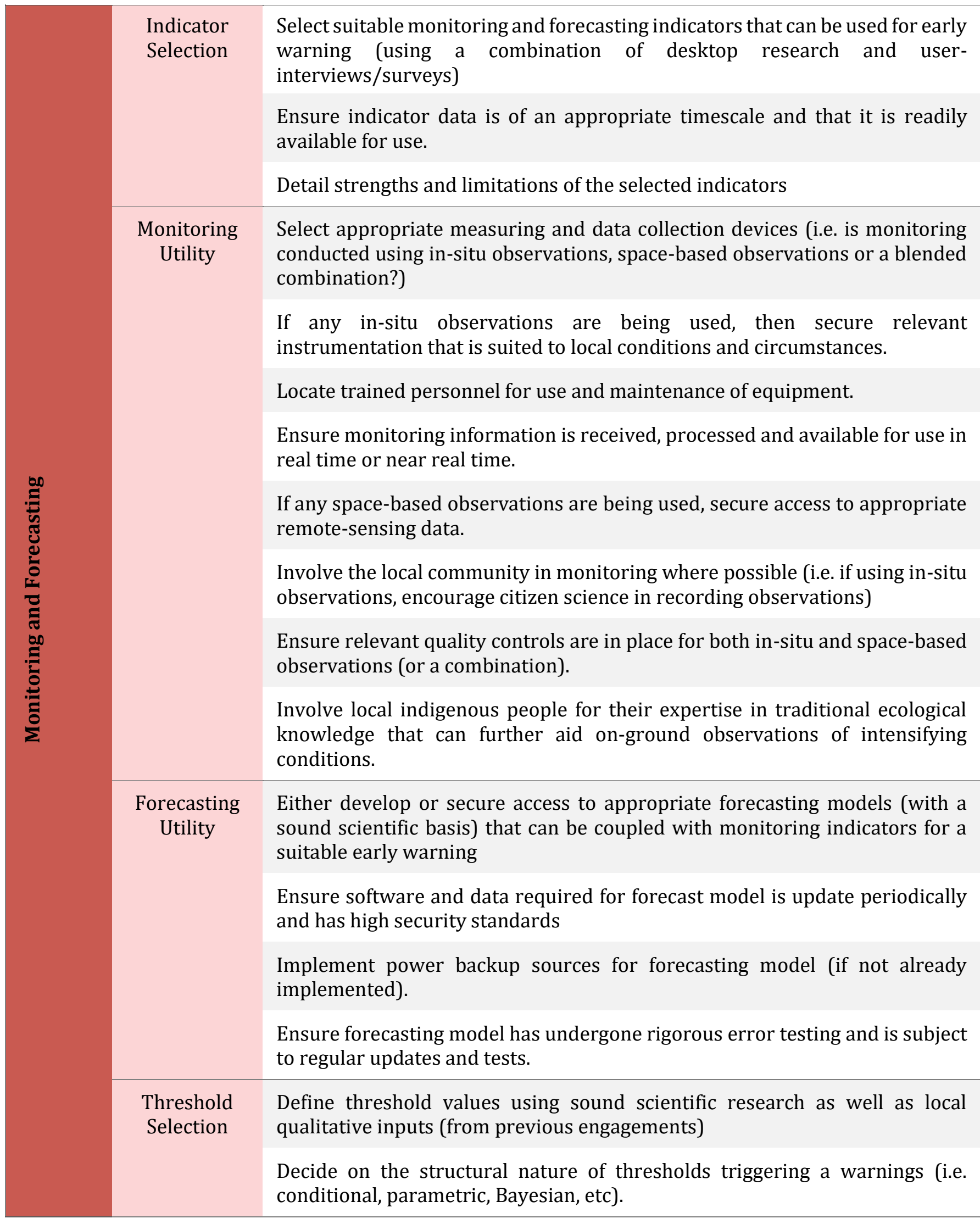




\begin{tabular}{|c|c|c|}
\hline \multirow{14}{*}{$\stackrel{0}{\stackrel{0}{\overparen{T}}}$} & \multirow[t]{5}{*}{$\begin{array}{l}\text { Communication } \\
\text { Structure }\end{array}$} & $\begin{array}{l}\text { Prepare a warning message template with clear, understandable and } \\
\text { informal language, include: } \\
\text { - WHY-Forecasted situation with possible consequences of inaction } \\
\text { - WHEN-Expected time of event and time of evacuation (with clear } \\
\text { differentiation) } \\
\text { - WHERE-Places and areas most at risk } \\
\text { - WHAT-How to evacuate and any potential actions to take }\end{array}$ \\
\hline & & Select a warning chime or sound that is distinct to the EWS \\
\hline & & $\begin{array}{l}\text { Ensure warnings are prepared in all spoken and read languages within the } \\
\text { region }\end{array}$ \\
\hline & & $\begin{array}{l}\text { Ensure warnings are easily understood by any potential transient } \\
\text { communities }\end{array}$ \\
\hline & & $\begin{array}{l}\text { Pre-test warning efficacy and understandability on stakeholders and users } \\
\text { before time of disaster if possible }\end{array}$ \\
\hline & \multirow[t]{9}{*}{$\begin{array}{l}\text { Warning } \\
\text { Dissemination }\end{array}$} & $\begin{array}{l}\text { Use multiple information sources that are trusted by locals and repeat the } \\
\text { message many times }\end{array}$ \\
\hline & & $\begin{array}{l}\text { Ensure that dissemination channels reach all at risk (i.e. SMS } \\
\text { communication may not reach certain low-socioeconomic communities } \\
\text { and alternative informal communication dissemination may be needed) }\end{array}$ \\
\hline & & $\begin{array}{l}\text { Conduct regular coordination, planning and review meetings for all } \\
\text { warning issuers, local media and other disseminating bodies }\end{array}$ \\
\hline & & $\begin{array}{l}\text { Consider informal sources of warning dissemination most relevant to the } \\
\text { community at risk (i.e. church groups, trusted community elders, etc.) }\end{array}$ \\
\hline & & $\begin{array}{l}\text { Generate and disseminate warning in an efficient and timely manner so } \\
\text { that vulnerable populations have time to act-in the case of fast-onset } \\
\text { events (i.e. floods, tropical cyclones) consider automating warning } \\
\text { dissemination. }\end{array}$ \\
\hline & & $\begin{array}{l}\text { Verify that all dissemination channels (SMS, radio, web, TV, informal, } \\
\text { sirens, bells, public address systems, door-to-door visits, community } \\
\text { meetings, etc.) are active, with high coverage and are able to disseminate } \\
\text { information rapidly }\end{array}$ \\
\hline & & $\begin{array}{l}\text { Develop feedback mechanisms to verify that severe to extreme warnings } \\
\text { have been received. }\end{array}$ \\
\hline & & $\begin{array}{l}\text { Develop agreements to utilize private sector resources where needed (i.e. } \\
\text { cellular services, satellite, television, radio, social media etc.) }\end{array}$ \\
\hline & & Inform community when a threat has ended. \\
\hline
\end{tabular}




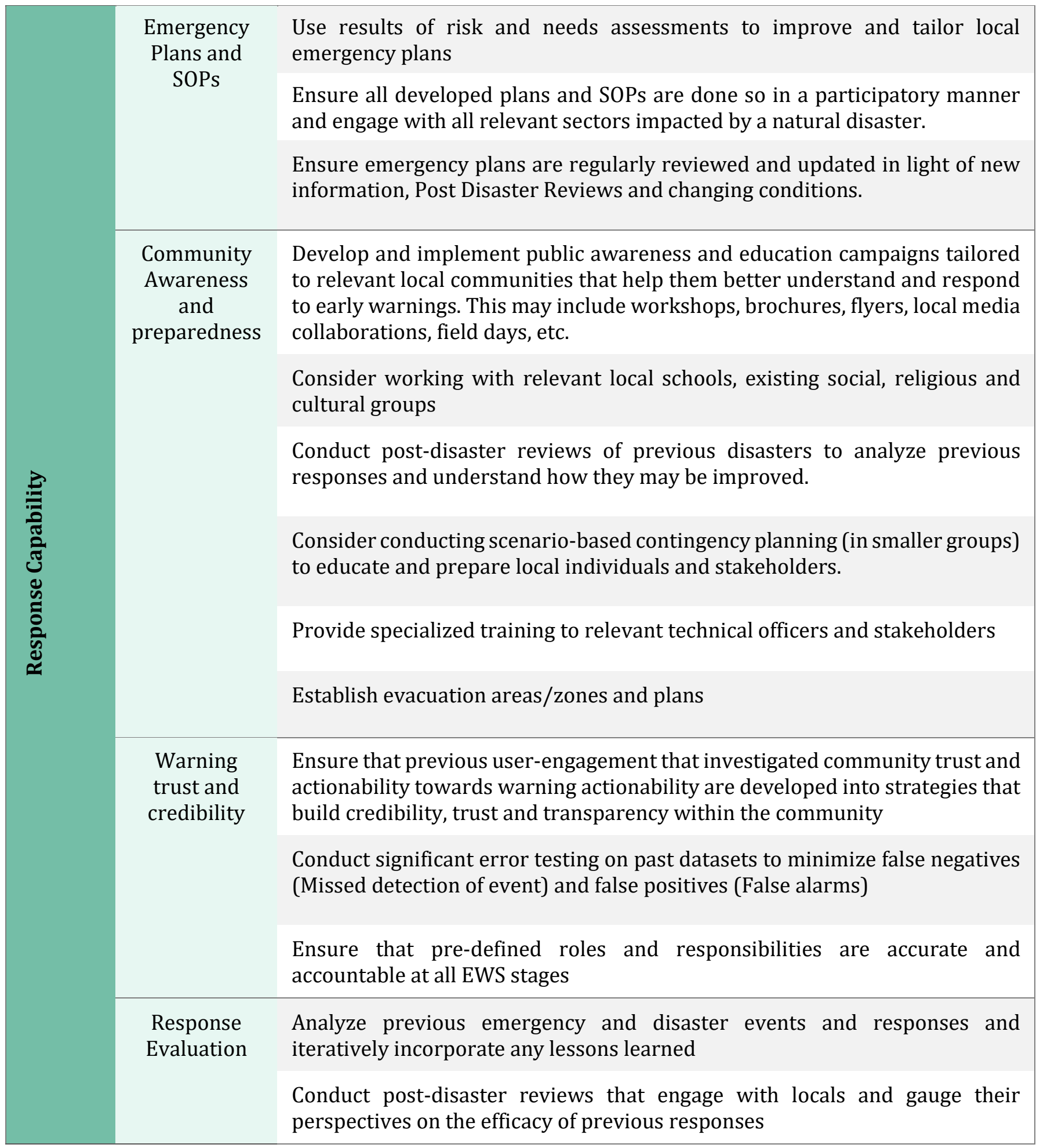




\section{References}

"What can go wrong with a Forecast-based Financing project?", accessed December 14th. https://www.forecast-based-financing.org/ourprojects/what-can-go-wrong/.

Abarquez, Imelda, and Zubair Murshed. 2004. Field Practitioners' Handbook: Asian Disaster Preparedness Center Bangkok.

Aitkenhead, I. 2020. "Assessing Agricultural Drought Management Strategies in the Northern Murray Darling Basin." School of Science, Monash University.

Aitkenhead, I., A. Asghari, and J. Bhardwaj. 2020. "Generating proactive, localised and inclusive responses to drought-a case study in the Goondiwindi Region of Southern Queensland." School of Science, Monash University.

Andersson, Lotta, Julie Wilk, L. Phil Graham, Jacob Wikner, Suzan Mokwatlo, and Brilliant Petja. 2019. "Local early warning systems for drought-Could they add value to nationally disseminated seasonal climate forecasts?" Weather and Climate Extremes.

Asghari, A. 2020. "Improving drought resilience in northern Murray-Darling Basin farming communities through proactive assistance." School of Science, Monash University.

Australian Bureau of Statistics (ABS). 1988. "Drought in Australia."

Bangladesh Red Crescent Society. 2019. Forecast-Based Financing (FbF) Flood Early Action Protocol (EAP) Bangladesh.

Banholzer, Sandra, James Kossin, and Simon Donner. 2014. "The Impact of Climate Change on Natural Disasters." In Reducing Disaster: Early Warning Systems for Climate Change, edited by Ashbindu Singh and Zinta Zommers, 21-49. Dordrecht: Springer Netherlands.

Basher, Reid. 2006. "Global early warning systems for natural hazards: systematic and people-centred." Philosophical Transactions of the Royal Society A: Mathematical, Physical and Engineering Sciences 364 (1845):2167-2182. https://doi.org/10.1098/rsta.2006.1819.

Baudoin, Marie-Ange, Sarah Henly-Shepard, Nishara Fernando, Asha Sitati, and Zinta Zommers. 2016. "From Top-Down to "Community-Centric" Approaches to Early Warning Systems: Exploring Pathways to Improve Disaster Risk Reduction Through Community Participation." International Journal of Disaster Risk Science 7 (2):163-174. https://doi.org/10.1007/s13753-016-0085-6.

Behlert, Benedikt, Rouven Diekjobst, Carsten Felgentreff, Timeela Manandhar, Peter Mucke, Ludger Pries, Katrin Radtke, and Daniel Weller. 2020. "The WorldRiskReport 2020." In, 43-51. Bündnis Entwicklung Hilft,
Bhardwaj, J. 2020. "Building Capacity for an Integrated people-centred Early Warning System (I-EWS) for Drought in the Northern Murray Darling Basin." School of Science, Monash University.

Brouwer, R., S. Akter, L. Brander, and Haque E. 2007. "Socioeconomic Vulnerability and Adaptation to Environmental Risk: A Case Study of Climate Change and Flooding in Bangladesh." Risk Analysis 27:313-326. https://doi.org/10.1111/i.15396924.2007.00884.x.

Bureau of Meteorology (BoM). 2020. Special Climate Statement 70-drought conditions in eastern Australia and impact on water resources in the Murray-Darling Basin.

Cinco, T.A., R.G. de Guzman, A.M.D. Ortiz, R.J.P. Delfino, R.D. Lasco, F.D. Hilario, E.L. Juanillo, R. Barba, and E.D. Ares. 2016. "Observed trends and impacts of tropical cyclones in the Philippines." International journal of Climatology 36 (14):4638-4650. /https://doi.org/10.1002/joc.4659.

Cobon, David H., Grant S. Stone, John O. Carter, Joe C. Scanlan, Nathan R. Toombs, Xike Zhang, Jacqui Willcocks, and Greg M. McKeon. 2009. "The climate change risk management matrix for the grazing industry of northern Australia." The Rangeland Journal 31 (1):31-49. https://doi.org/10.1071/RJ08069.

Coughlan de Perez, E., Bjjm van den Hurk, M. K. Van Aalst, B. Jongman, T. Klose, and P. Suarez. 2015. "Forecast-based financing: an approach for catalyzing humanitarian action based on extreme weather and climate forecasts." Natural Hazards and Earth System Sciences 15 (4):895-904.

Coughlan de Perez, Erin, Bart van den Hurk, Maarten K. van Aalst, Irene Amuron, Deus Bamanya, Tristan Hauser, Brenden Jongma, Ana Lopez, Simon Mason, and Janot Mendler de Suarez. 2016. "Action-based flood forecasting for triggering humanitarian action." Hydrology and Earth System Sciences 20 (9):3549-3560.

Dayal, Kavina S., Ravinesh C. Deo, and Armando A. Apan. 2018. "Spatio-temporal drought risk mapping approach and its application in the drought-prone region of south-east Queensland, Australia." Natural Hazards $93 \quad$ (2):823-847. https://doi.org/10.1007/s11069-018-3326-8.

de León, Juan Carlos Villagran, Janos Bogardi, Stefanie Dannenmann, and Reid Basher. 2006. "Early warning systems in the context of disaster risk management." Entwicklung and Ländlicher Raum 2:23-25.

Diamond, H. 2020. "Southwest Pacific Enhanced Archive for Tropical Cyclones (SPEArTC)." accessed 4 January. 
Docker, Benjamin, and Ian Robinson. 2014. "Environmental water management in Australia: experience from the Murray-Darling Basin." International Journal of Water Resources Development $\quad 30 \quad$ (1):164-177. https://doi.org/10.1080/07900627.2013.79203 $\underline{9}$.

Feeny, S. and McGillivray, M. 2010. "Aid and growth in Small Island developing states." Journal of Development Studies 46 (5):897-917. https://doi.org/10.1080/00220381003623889.

Garcia, Carolina, and Carina Fearnley. 2012. "Evaluating Critical Links in Early Warning Systems." Environmental Hazards 11:123-137. https://doi.org/10.1080/17477891.2011.60987 7.

Garcia Londoño, Carolina. 2011. "Mountain Risk Management: Integrated People Centred Early Warning System as a risk reduction strategy, Northern Italy." PhD. Progr, University of MilanoBicocca.

Global Disaster Alert and Coordination System (GDAC). 2017. CycloneWinston_StormSurge. edited by ArcGIS.

Government of Fiji. 2016. Fiji post-disaster needs assessment, tropical cyclone Winston, February 20, 2016. edited by Government of Fiji. Suva.

Hart, Barry T. 2016. "The Australian Murray-Darling Basin Plan: challenges in its implementation (part 1)." International Journal of Water Resources Development $32 \quad$ (6):819-834. https://doi.org/10.1080/07900627.2015.10838 47.

HDX. 2019a. Fiji Administrative Boundaries.

HDX. 2019b. HOTOSM Fiji (east) Roads. edited by OpenStreetMap Export.

HDX. 2019c. HOTOSM Fiji (west) Roads. edited by OpenStreetMap Export.

Heinrich, D., and M. Bailey. 2020. Forecast-based financing and early action for drought: Guidance notes for the Red Cross Red Crescent.

Hennessy, K., Scott Power, and Gillian Cambers. 2011. Climate Change in the Pacific: Scientific Assessment and New Research. Volume 1, Regional Overview.

Hidayat, Benny, and C. O. Egbu. 2010. "A literature review of the role of project management in post-disaster reconstruction." 2010.

Ho, Elaine. 2018. "Criteria-based ranking (CBR): A comprehensive process for selecting and prioritizing monitoring indicators." MethodsX 5:1324-1329.

https://doi.org/10.1016/j.mex.2018.10.015.

Hughes, Neal, David Galeanol, and Steve Hatfield-Dodds. 2019. The effects of drought and climate variability on Australian farms. Canberra: Australian Bureau of Agricultural Resource Economics and Sciences (ABARES).
Intergovernmental Panel on Climate Change. 2014. IPCC Fifth Assessment Report (AR5) edited by (Core Writing Team-R.K. Pachauri and L.A. Meyer (eds.)). Geneva, Switzerland.

Jacka, Jerry K. 2020. "In the Time of Frost: El Niño and the Political Ecology of Vulnerability in Papua New Guinea." Anthropological Forum 30 (1-2):141-156. https://doi.org/10.1080/00664677.2019.16478 $\underline{32}$.

Jacot Des Combes, H. 2019. "Storm Surges, Heavy Rain and Strong Wind: Impacts of Tropical Cyclone Winston in Fiji-Focus on Health." Extreme Weather Events and Human Health:185196.https://doi.org/10.1007/978-3-030-23773$\underline{8}$.

Kelman, Ilan, Jessica Mercer, and J. C. Gaillard. 2012. "Indigenous knowledge and disaster risk reduction." Geography 97:12-21.

Knutson, Thomas, John McBride, Johnny Chan, Kerry Emanuel, Greg Holland, Christopher Landsea, Isaac Held, James Kossin, A. Srivastava, and Masato Sugi. 2010. "Tropical Cyclones and Climate Change." Nature Geoscience 3. https://doi.org/10.1038/ngeo779.

Kuleshov, Yuriy, Kasis Inape, Andrew Watkins, Adele BearCrozier, Zhi-Weng Chua, Pingping Xie, Takuji Kubota, Tomoko Tashima, Robert Stefanski, and Toshiyuki Kurino. 2019. "Climate Risk and Early Warning Systems (CREWS) for Papua New Guinea." In.

Lagmay, A.M.F., R.P. Agaton, M.A.C. Bahala, J.B.L.T. Briones, K.M.C. Cabacaba, C.V.C. Caro, L.L. Dasallas, L.A.L. Gonzalo, C.N. Ladiero, J.P. Lapidez, M.T.F. Mungcal, J.V.R. Puno, M.M.A.C. Ramos, J. Santiago, J.K. Suarez, and J.P. Tablazon. 2015. "Devastating storm surges of Typhoon Haiyan." International Journal of Disaster Risk Reduction 11:1-12. https://doi.org/10.1016/j.ijdrr.2014.10.006.

Macherera, Margaret, and Moses J. Chimbari. 2016. "A review of studies on community based early warning systems." Jamba (Potchefstroom, South Africa) 8 https://doi.org/10.4102/jamba.v8i1.206.

Marchezini, Victor, Rachel Trajber, Débora Olivato, Viviana Aguilar Muñoz, Fernando de Oliveira Pereira, and Andréa Eliza Oliveira Luz. 2017. "Participatory Early Warning Systems: Youth, Citizen Science, and Intergenerational Dialogues on Disaster Risk Reduction in Brazil." International Journal of Disaster Risk Science 8 (4):390-401. https://doi.org/10.1007/s13753-017-0150-9.

Méheux, K., Dominey-Howes, D. and Lloyd, K. 2007. "Natural hazard impacts in small island developing states: A review of current knowledge and future research needs." Natural Hazards 40 (2):429-446. https://doi.org/10.1007/s11069006-9001-5. 
Mercer, Jessica. 2010. "Disaster Risk Reduction or Climate Change Adaptation: Are We Reinventing the Wheel?" Journal of International Development 22:247-264. https://doi.org/10.1002/iid.1677.

Mercer, Jessica, Dale Dominey-Howes, Ilan Kelman, and Kate Lloyd. 2007. "The potential for combining indigenous and western knowledge in reducing vulnerability to environmental hazards in small island developing states." Environmental Hazards 7(4):245-256. https://doi.org/10.1016/j.envhaz.2006.11.001.

Merz, Bruno, Christian Kuhlicke, Michael Kunz, Massimiliano Pittore, Andrey Babeyko, David N. Bresch, Daniela I. V. Domeisen, Frauke Feser, Inga Koszalka, Heidi Kreibich, Florian Pantillon, Stefano Parolai, Joaquim G. Pinto, Heinz Jürgen Punge, Eleonora Rivalta, Kai Schröter, Karen Strehlow, Ralf Weisse, and Andreas Wurpts. 2020. "Impact Forecasting to Support Emergency Management of Natural Hazards." Reviews of $\begin{array}{lll}\text { Geophysics } & 58 & \text { (4):e2020RG000704. }\end{array}$ https://doi.org/10.1029/2020RG000704.

Mileti, Dennis S., and John H. Sorensen. 1990. Communication of emergency public warnings: A social science perspective and state-of-the-art assessment. Oak Ridge National Lab., TN (USA).

National Disaster Risk Reduction and Management Council. 2014. Updates re the Effects of Typoon Yolanda.

Open Street Map. 2016a. Fiji Comms. edited by ArcGIS.

Open Street Map. 2016b. Fiji Hospitals. edited by ArcGIS.

Philippine Red Cross. 2019. Typhoon Early Action Protocol.

Productivity Commission. 2005. Trends in Australian Agriculture. Canberra.

Productivity Commission. 2009. Government Drought Support-Productivity Commission Inquiry Report. Melbourne.

Quiggin, John, David Adamson, Sarah Chambers, and Peggy Schrobback. 2010. "Climate Change, Uncertainty, and Adaptation: The Case of Irrigated Agriculture in the Murray-Darling Basin in Australia." Canadian Journal of Agricultural Economics/Revue canadienne d'agroeconomie 58 (4):531-554. https://doi.org/10.1111/j.17447976.2010.01200.x.

Ruhr University Bochum-Institute for International Law of Peace and Armed Conflict (IFHV).

Sena, Aderita, Kristie L. Ebi, Carlos Freitas, Carlos Corvalan, and Christovam Barcellos. 2017. "Indicators to measure risk of disaster associated with drought: Implications for the health sector." PloS one 12 (7):e0181394-e0181394. https://doi.org/10.1371/journal.pone.0181394.

Statistics for Development Division. 2019. PopGIS3-Fiji. edited by PopGIS.

Svoboda, Mark, and Brian Fuchs. 2016. "Handbook of Drought Indicators and Indices."
Terry, James P., and A. Y. Annie Lau. 2018. "Magnitudes of nearshore waves generated by tropical cyclone Winston, the strongest landfalling cyclone in South Pacific records. Unprecedented or unremarkable?" Sedimentary Geology 364:276285.

https://doi.org/10.1016/j.sedgeo.2017.10.009.

Twigg, John. 2015. Disaster risk reduction: Overseas Development Institute, Humanitarian Policy Group London.

United Nations Development Programme (UNDP). 2018. Five Approaches to Build Functional Early Warning Systems. Geneva, Switzerland.

United Nations Office for Disaster Risk Reduction. 2004. "Basic Terms of Disaster Risk Reduction." Living with Risk: A Global Review of Disaster Reduction Initiatives.

United Nations Office for Disaster Risk Reduction (UNDRR), and United Nations Development Programme (UNDP). 2012. "Disaster risk reduction and climate change adaptation in the Pacific: an institutional and policy analysis." Suva, Fiji: UNISDR, UNDP, 76pp.

Wamsler, Christine, and Nigel Lawson. 2012. "Complementing institutional with localised strategies for climate change adaptation: a SouthNorth comparison." Disasters 36 (1):28-53.

Webb, Julie. 2020. "What difference does disaster risk reduction make? Insights from Vanuatu and tropical cyclone Pam." Regional Environmental Change 20. https://doi.org/10.1007/s10113020-01584-y.

Wilhite, Donald A., Mannava V. K. Sivakumar, and Roger Pulwarty. 2014. "Managing drought risk in a changing climate: The role of national drought policy." Weather and Climate Extremes 3:4-13. https://doi.org/10.1016/i.wace.2014.01.002.

Williges, Keith, Reinhard Mechler, Paul Bowyer, and Juraj Balkovic. 2017. "Towards an assessment of adaptive capacity of the European agricultural sector to droughts." Climate Services 7:47-63. https://doi.org/10.1016/i.cliser.2016.10.003.

World Meteorological Organization (WMO). 2014. PostTyphoon Haiyan (Yolanda) Expert Mission to the Philippines, Manila and Tacloban, 7-12 April 2014, Mission Report

World Meteorological Organization (WMO). 2015. "WMO Guidelines on Multi-hazard Impact-based Forecast and Warning Services.".

World Meteorological Organization (WMO). 2018. Multihazard Early Warning Systems: A Checklist. Geneva, Switzerland.

World Resources Institute. 2011. Reefs at Risk Revisited. edited by World Resources Institute. 
Yin, Yuanyuan, Xingming Zhang, Degen Lin, Han Yu, Jing'ai Wang, and Peijun Shi. 2014. "GEPIC-V-R model: A GIS-based tool for regional crop drought risk assessment." Agricultural Water Management 144:107-119.

https://doi.org/10.1016/j.agwat.2014.05.017.

Atifa Asghari is a Mathematical Science graduate from Monash University (Australia). During her Honours research year in 2020, she investigated the feasibility of a Forecast-based Financing system to be implemented in an Australian context to increase drought proactivity. She worked closely with Yuriy Kuleshov and team members Isabella Aitkenhead and Jessica Bhardwaj to propose a drought response strategy to stakeholders. She has a close interest in how governments and agencies can collaborate with vulnerable communities to manage disaster risk reduction strategies (specifically financial management) for developing and least developed countries.

Isabella Aitkenhead is an Advanced Science and Global Challenges graduate from Monash University (Australia), with a major in Ecology and Conservation Biology. Her Honours research was focused on drought risk assessments specifically in Australia whilst considering applicability for use in other drought-vulnerable countries. She has a keen interest in climate adaptation and disaster risk reduction with specific interest in forming more positive relationships between people and the environment. During her Honours research year, she realized how important the response of local vulnerable communities to natural hazards is. She wanted to improve risk knowledge for vulnerable communities in order to increase their capacity to proactively and appropriately response to natural hazards such as drought.

Madeleine Jackson is an Environmental Science BSc graduate from the University of Liverpool (UK). As part of her final year dissertation, she investigated the interannual variability of tropical cyclones in Fiji and their impacts. Through an exchange semester at the Royal Melbourne Institute of Technology (RMIT) University in Melbourne (Australia) she met Yuriy Kuleshov who provided her with extensive tropical cyclone data. Her dissertation research has now been incorporated into this project for JSPG. In 2017, she took part in a volunteering project to Fiji. During her time there she experienced a tropical cyclone which led to her interest in this topic. She was able to engage with the local community and see the devastation caused, therefore she wanted her research to contribute towards reducing these impacts.

Jessica Bhardwaj is a physical science graduate from Monash University (Australia) and recent PhD candidate with the Royal Melbourne Institute of Technology (RMIT) University. In 2020 she undertook her Honours research project investigating the early prediction, detection and communication of drought and its related impacts in Australia's Northern Murray Darling Basin. This research made her interested in the development and implementation of user-centered Early Warning Systems for Disaster Risk Reduction in hazard-vulnerable communities around the world. She is currently a researcher with the Bureau of Meteorology in Australia, investigating the potential for such systems in Pacific Island countries such as Papua New Guinea and Vanuatu.

Yuriy Kuleshov is a climate scientist; his current roles are a Science Lead for the Climate Risk and Early Warning Systems (CREWS) projects at the Australian Bureau of Meteorology; Adjunct Professor at the SPACE Research Centre, Royal Melbourne Institute of Technology (RMIT) University; Chairman of the World Meteorological Organization (WMO) Space-based Weather and Climate Extremes Monitoring (SWCEM), among others. Yuriy is passionate about guiding the younger generation of scientists on climate research.

\section{Acknowledgements}

The authors would like to acknowledge the various participants from the multiple qualitative studies. We are particularly grateful for the various participant and stakeholder insights from Northern MDB communities. 


\section{Disclaimer}

All case studies were conducted as a part of junior authors' Honours programs under the supervision of Prof. Yuriy Kuleshov. The EWS and Risk Assessment case study results are published in detail at https://doi.org/10.1007/s11069-021-04575-2 